\title{
Multifunctional Ternary Drug-Loaded Electrospun Scaffolds
}

\author{
Elena Llorens ${ }^{1}$, Luis J. del Valle ${ }^{1, *}$, Jordi Puiggalí ${ }^{1,2}$
}

${ }^{1}$ Departament d'Enginyeria Química, Universitat Politècnica de Catalunya, Av. Diagonal 647, Barcelona E-08028, Spain.

${ }^{2}$ Center for Research in Nano-Engineering (CrNE), Universitat Politècnica de Catalunya, Edifici C, C/Pasqual i Vila s/n, Barcelona E-08028, Spain.

Corresponding Author: luis.javier.del.valle@upc.edu 


\section{ABSTRACT}

Multifunctional electrospun scaffolds were prepared from two PLA grades having slightly different D-lactide content (4.2 wt-\% and 2.0 wt-\%). Triclosan (TCS), ketoprofen (KTP) and p-coumaric acid (CUM) were selected as bactericide, antiinflammatory and antioxidant agents, respectively. Single, binary and ternary drugloaded microfibers having a unimodal diameter distribution could be prepared using a common chloroform:acetone:dimethylsulfoxide mixture and similar operational parameters (i.e. voltage, flow rate and tip-collector distance). FTIR spectra were sensitive to the low amount of drugs loaded and even showed slight differences in PLA conformation. DSC heating scans clearly demonstrated the ability of electrospinning to induce molecular orientation of PLA and also the nucleation effect of incorporated drugs to induce crystallization. Thus, crystallinity of binary drug-loaded scaffolds was significantly higher than observed for unloaded samples.

Release behavior of the three drugs from loaded scaffolds and PLA matrices in PBS: ethanol medium was evaluated. A rapid release was always detected, together with partial drug retention which was higher when the more stereoregular PLA matrix was employed. A strong bactericide effect was found when scaffolds were loaded with 3 $w / v-\%$ of TCS, but incorporation of a small percentage of KTP (i.e. $1 w / v-\%$ ) had a bacteriostatic effect even in the absence of TCS. The inherent cytotoxicity of TCS could be well neutralized by enhancing cell viability by incorporation of CUM and/or KTP. 


\section{INTRODUCTION}

The development of scaffolds that could mimic natural tissues is a basic point for tissue engineering and regenerative medicine applications. These scaffolds can be specifically prepared to display biological activities that induce regeneration of both tissues and organs and restore the function of diseased or traumatized tissues in the human body. ${ }^{1}$

Scaffolds are defined as three-dimensional porous solid biomaterials which should offer a unique combination of inherent properties, such as to provide physical stability at the implanted injury site. Besides promoting tissue regeneration, scaffolds have other very important characteristics/functions: (i) ability to favor cell-biomaterial interactions (i.e. cell adhesion and extracellular matrix (ECM) deposition); (ii) enhancement of cell survival (proliferation and differentiation); (iii) comparability of biodegradation rate with required time for tissue regeneration, and (iv) ability to cause minimum inflammation or toxicity in-vivo resulting from toxic metabolic byproducts. ${ }^{1}$ In addition, scaffolds can be used as carriers and/or delivery systems of drugs or biomolecules to palliate different stages during replacement and regeneration of tissue or to avoid rejection of implanted biomaterial.

Natural and synthetic polymers have been widely used as biomaterials for medical devices and tissue-engineering scaffolds. ${ }^{2,3}$ The most commonly used synthetic polymers in tissue engineering are polylactide (PLA), polyglicolide (PGA) and their copolymers (PLGA). ${ }^{4}$ These materials provide synthetic scaffolds characterized by excellent mechanical properties, highly interconnected porous structure, ability to activate their surfaces to yield specific chemical properties, and geometry adapted to direct tissue regeneration. ${ }^{5}$ 
Different techniques to prepare scaffolds are currently available, but electrospinning is probably one of the simplest processes to obtain porous matrices constituted by fibers in the micrometer and nanometer scales. Furthermore, since fibers can be easily loaded with drugs during their preparation, electrospinning provides the most promising results for tissue engineering, tissue regeneration and drug delivery applications. ${ }^{6,7}$ Specifically, electrospun scaffolds can be used for musculoskeletal tissue engineering including bone and cartilage, and also as control delivery systems for drugs, proteins and DNA. ${ }^{8}$ Electrospinning has been widely applied to obtain scaffolds from natural polymers such as collagen, ${ }^{9}$ gelatin, ${ }^{10}$ chitosan, ${ }^{11} \mathrm{HA},{ }^{12}$ and silk fibroin, ${ }^{13}$ as well as synthetic polymers like polylactide,${ }^{14}$ polyurethane,${ }^{15}$ polycaprolactone,${ }^{16}$ poly(lactideco-glicolide), ${ }^{17}$ polyvinilalcohol, ${ }^{18}$ and poly(lactide-co-caprolactone). ${ }^{5}$ Furthermore, electrospinning is a suitable technique for processing mixtures of polymers to get materials that combine the properties of the individual components. For example, combination of biodegradable and conducting/electroactive polymers is receiving nowadays great attention to give rise to advanced materials for local stimulation of tissues or the stimulation of either the proliferation and differentiation of cells. ${ }^{19,20}$

Several health problems have been associated with the use of biomaterials, for example infection related to the use of catheters ${ }^{21}$ or prosthetic bones, among others. ${ }^{22}$ Other problems concerning damaged tissue, such as inflammation produced by cell necrosis, must be considered, too. Inflammation and oxidative stress are two cellular processes in the tissue that must be treated to restart rapid recovery from tissue injury. In this sense, scaffolds should be designed to be used not only as appropriate platforms to support cell proliferation but also as active elements to mediate cell recovery through local tissue medication. 
Great efforts have been focused to the development of antibacterial nanofibers through electrospinning. ${ }^{23}$ Different systems have specifically been considered taking into account the substrate polymer (e.g., polylactide and polycaprolactone), the antibacterial agent (e.g., antibiotic, bactericide, silver and metal oxide nanoparticles and chitosan) and the selected method to incorporate the drug (e.g., incorporation of the agent in the electrospinning solution, coaxial electrospinning, conversion of a precursor to its active form by a post-treatment, previous encapsulation of the antibacterial agent and attachment of the active agent onto the fiber surface). Triclosan is probably one of the most employed bactericide agent as indicated in Table 1.

\section{[TABLE 1]}

A problem concerning the use of biodegradable polymers (e.g., PLA) is that their degradation products often cause severe foreign body reaction and an inflammatory response. Different non-steroidal and anti-inflammatory drugs like ibuprofen or ketoprofen have long been used (Table 1) to improve performance of electrospun scaffolds. A clear advantage of electrospinning is the possibility to incorporate these poorly soluble drugs into the fibrous matrix system.

In recent years, the stress oxidative has been identified as a cause of several human diseases, so the application of antioxidants as therapeutic agent has an increased interest for the medical treatment. The biological system has a proper balance between the formation and removal of the reactive oxygen species. Also, transplantation of organ and tissues has more success when stress oxidative is reduced by the administration of

molecules with antioxidant activity. ${ }^{24,25}$ Although there are very few reports about of devices and scaffolds loaded with antioxidants, some of them merit attention, e.g. those concerning mats of electrospun cellulose acetate fibers containing asiaticoside or 
curcumin, ${ }^{26}$ vitamin $\mathrm{A}$ acid or vitamin $\mathrm{E},{ }^{27}$ as well as polyesters like polycaprolactone and polylactide loaded with curcumin, ${ }^{28}$ and gallic acid, ${ }^{29}$ respectively. Furthermore, polylactide (PLA) has also been loaded with vitamin $\mathrm{B}_{6}$ and hydroxycinnamic acids (e.g., p-coumaric and caffeic acids). ${ }^{30}$ Thus, new electrospun fibers matrices loaded with antioxidant molecules can reduce pro-oxidative damage in cells grown onto these materials (Table 1). The presence of a high amount of reactive oxygen species in an injured tissue generates a harmful environment, which could cause a rejection of the biomaterial. In conclusion, scaffolds functionalized with antioxidants can be used as platforms for tissue engineering. ${ }^{30}$

Electrospinning is a simple and cost-effective technique that could be employed to get multifunctional scaffolds by the simultaneous load of appropriate agents. Incorporation of bactericide agents and growth factors is for example highly interesting to develop wound dressings able to treat infection and healing chronic wounds. ${ }^{31}$ Despite this great potential, scarce works refer to preparation of multifunctional systems. In particular ternary systems based on bactericide, anti-inflammatory and antioxidant agents have not been considered up to now at the best of our knowledge.

TCS has a well demonstrated antimicrobial activity against both for Gram-negative and Gram-positive bacteria. Thus, TCS has been extensively used for topical applications, and its controlled release from biomaterials evaluated. ${ }^{30,34}$ CUM is an hydroxycinnamic acid with a recognized activity as scavenger for the prevention of the oxidative stress damage produced by free radicals. ${ }^{35,36} \mathrm{KTP}$ is a non-steroidal anti-inflammatory drug (NSAID) used to control pain and inflammation in rheumatic diseases, being also effective as an anti-inflammatory agent in humans with flogistic diseases. ${ }^{37,38}$

\section{[FIGURE 1]}


The goal of this work is the preparation of multiactive electrospun scaffolds that could represent an improved material for the regeneration and repair of a damaged tissue. Specifically avoid rejection, palliate possible bacterial activity and possible inflammation during the tissue regeneration. To this end, triclosan (TCS), p-coumaric acid (CUM) and ketoprofen (KTP) drugs (Figure 1) with antimicrobial, antioxidant, anti-inflammatory activities, respectively, will be loaded to two polylactide (PLA) grades having a slightly different stereoregularity and consequently thermal, degradation and mechanical properties. ${ }^{32,33}$ The scaffold morphology, physicochemical properties, drug release profiles, antimicrobial activity and biocompatibility of scaffolds are presented.

\section{EXPERIMENTAL}

\section{Materials}

Two commercial PLA grades from Natureworks ${ }^{\circledR}$ differing on the lactic acid content were used. Specifically, PLA 2002D and PLA 4032D samples having 95.8 and $98 w t-\%$ of L-lactic were selected. PLA 2002D is a transparent solid with a density of $1.24 \mathrm{~g} / \mathrm{cc}$, being its calorimetric and mechanical properties defined by a glass transition temperature $\left(T_{g}\right)$ of $58^{\circ} \mathrm{C}$, a melting point $\left(T_{m}\right)$ of $153{ }^{\circ} \mathrm{C}$, a tensile modulus $(E)$ of 3500 MPa, a tensile strength $(\sigma)$ of 53-60 MPa and a tensile elongation $(\gamma)$ of $6 \%$. PLA 4032D has a translucent appearance, a density of $1.24 \mathrm{~g} / \mathrm{cc}$ and highly different properties from those of the sample with higher D content. Thus, $T_{g}, T_{m}, E, \sigma$ and $\gamma$ values were reported to be $70{ }^{\circ} \mathrm{C}, 160{ }^{\circ} \mathrm{C}, 3440-3784 \mathrm{Ma}, 103.2-144.5 \mathrm{MPa}$ and $100-$ $180 \%$, respectively. Molecular weights determined by GPC were quite similar, and specifically $M_{n}, M_{w}$ and polydispersity index were $98,100 \mathrm{~g} / \mathrm{mol}, 181,000 \mathrm{~g} / \mathrm{mol}$ and 1.85 for PLA $2002 \mathrm{D}$ and $84,200 \mathrm{~g} / \mathrm{mol}, 179,400 \mathrm{~g} / \mathrm{mol}$ and 2.13 for PLA 4032D. ${ }^{32,63}$ 
Trichloromethane (or chloroform), acetone, dimethylsulfoxide (DMSO), triclosan $\left(\operatorname{Irgasan}^{\mathrm{TM}}\right)(\mathrm{TCS})$, ketoprofen (KTP) and 3-(4,5-dimethylthiazol-2-yl)-2,5-diphenyl2H-tetrazolium bromide (MTT) were purchased from Sigma-Aldrich (St. Louis, USA) and p-coumaric acid (CUM) was purchased from Acros Organics (New Jersey, USA).

VERO (African green monkey kidney epithelial cells) and MDCK (Madin-Darby canine kidney epithelial cells) were purchased from ATCC (USA). Escherichia coli CECT 101 and Micrococcus luteus CECT 245 bacteria strains were obtained from the Spanish Collection of Type Culture (Valencia, Spain).

\section{Preparation of fibers by electrospinning}

Both PLA 2002D and PLA 4032D (1 g) were dissolved in $9 \mathrm{~mL}$ of a chloroformacetone mixture $(2: 1 \mathrm{v} / \mathrm{v})$. Subsequently, drugs were dissolved in $1 \mathrm{~mL}$ of dimethysulfoxide (DMSO) that was added to the polymer solution. The mixture was homogenized by vortex to obtain an electrospinable solution of $10 \mathrm{w} / \mathrm{v}-\%$ PLA, and 3 $w / v-\%$ TCS, $1 w / v-\%$ KTP and $1 w / v-\%$ CUM. Furthermore, PLA samples loaded with one single drug and dual-drug combinations (i.e. TCS/CUM and KTP/CUM) were also prepared as controls.

A plastic syringe of $5 \mathrm{~mL}$ (Becton Dickson, Spain) was filled with the corresponding solution containing PLA and the selected combination of drugs. Electrospinning was carried out between the needle (18G; Terumo, Belgium) connected to the anode and the static collector connected to the cathode, being the needle-collector distance optimized. A high voltage supply (Gamma High Voltage Research, ES30-5W) was employed. All electrospinning experiments were conducted at room temperature (approx. $25^{\circ} \mathrm{C}$ ).

\section{Morphology and crystallinity of drug loaded PLA nanofibers}


Diameter measurements and inspection of fiber surfaces were performed by scanning electron microscopy using a Focus Ion Beam Zeiss Neon 40 instrument (Carl Zeiss, Germany). A Mitec K950 Sputter Coater equipped with a film thickness monitor $k 150 \mathrm{x}$ was used to coat the samples. Samples were viewed at an accelerating voltage of $5 \mathrm{kV}$.

Thermal properties were determined by differential scanning calorimetry with a TA Instruments Q100 series equipped with a refrigeration cooling system (RCS). Experiments were conducted under a flow of dry nitrogen with a sample weight of approximately $5 \mathrm{mg}$ and calibration was performed with indium. Heating and cooling runs were carried out at a rate of $20^{\circ} \mathrm{C} / \mathrm{min}$ and $10{ }^{\circ} \mathrm{C} / \mathrm{min}$, respectively.

FTIR spectra of unloaded and drug loaded PLA 4032D and PLA 2002D samples were recorded on a Jasco FTIR 4100 spectrophotometer dotted with an attenuated total reflection accessory (Specac MKII Golden Gate Heated Single Reflection Diamond ATR).

\section{Release experiments}

Controlled release experiments were performed with electrospun scaffolds cut into small square pieces $\left(20 \times 20 \times 0.1 \mathrm{~mm}^{3}\right)$. These samples were weighed and placed into polypropylene tubes. A typical phosphate buffered saline (PBS) supplemented with 70 $v / v-\%$ of ethanol and PBS with $10 v / v_{-} \%$ of serum were used as a release media. In addition, PBS was also considered as a control. The first medium was selected since is economical, allows an easy detection of the delivered drug (e.g. by UV-Vis spectroscopy) and may favour the release of hydrophobic drugs due to the incorporation of ethanol that in addition can diffuse within the polymer bulk. In this way, differences between the studied systems (e.g. influence of crystallinity of PLA matrices or type of loaded drug) can be highlighted using this system. Moreover, ethanol-saline mixtures 
were previously employed to simulate the usual serum supplemented medium, being found a good agreement for low ethanol content (i.e. 5\%-25\%) and drugs only loaded in surface-coatings. ${ }^{33}$

Drug release was carried out in $50 \mathrm{~mL}$ of the release medium at $25^{\circ} \mathrm{C}$ for 1 week. Drug concentration in both PBS-ethanol and PBS release media was evaluated by UV-Vis spectroscopy using a UV-3600 spectrophotometer (Shimadzu, Japan). Calibration curves were obtained by plotting the absorbance measured at the corresponding wavelengths against drug concentration. Specifically, measurements were performed at wavelengths of 257, 281 and $310 \mathrm{~nm}$ for KTP, TCS and CUM, respectively. Samples $(1 \mathrm{~mL})$ were drawn from the release medium at predetermined intervals and an equal volume of fresh medium was added to the release vessel. The amount of drug remaining in the scaffold was also determined by absorbance measurements. In this case, the sample was dissolved in chloroform and the drug subsequently extracted with ethanol. All the drug release tests were carried out using three replicates to control release homogeneity, and the results obtained from the samples were averaged.

In the case of a serum supplemented release medium scaffolds were removed after the selected exposure time, extensively washed with water, dried and finale dissolved in chloroform. The amount of remaining drug was again determined by UV-Vis measurements at the corresponding wavelengths.

\section{Antimicrobial test: assay of bacterial growth and adhesion}

The antimicrobial effect of electrospun scaffolds loaded with CUM, TCS/CUM, KTP/CUM and TCS/KTP/CUM was evaluated using both Gram-negative (Escherichia coli) and Gram-positive (Micrococcus luteus) bacteria. The bacteria were previously grown aerobically to exponential phase in broth culture $(5 \mathrm{~g} / \mathrm{L}$ beef extract, $5 \mathrm{~g} / \mathrm{L} \mathrm{NaCl}$, $10 \mathrm{~g} / \mathrm{L}$ peptone, $\mathrm{pH}$ 7.2). 
Growth experiments were performed in tubes of $15 \mathrm{~mL} \cdot 10^{3} \mathrm{CFU}$ (colony forming units) were seeded in $5 \mathrm{~mL}$ of broth culture containing the corresponding electrospun scaffolds. The cultures were incubated at $37^{\circ} \mathrm{C}$ and agitated at $80 \mathrm{rpm}$. After incubation for 24 and $48 \mathrm{~h}$, an aliquot of $100 \mu \mathrm{L}$ was diluted 10 times with distilled water. UV absorbance was measured at $600 \mathrm{~nm}$ and the bacterial number was determined using a McFarland curve scale. The relative growth (percentages) was graphically represented.

$10^{7}-10^{8}$ CFU were seeded in $5 \mathrm{~mL}$ of broth culture containing the corresponding electrospun scaffolds to perform the adhesion measurements. The cultures were incubated at $37^{\circ} \mathrm{C}$ and agitated at $80 \mathrm{rpm}$. After incubation, the cultures were aspired and the material washed once with distilled water. Subsequently, $1 \mathrm{~mL}$ of sterile $0.01 \mathrm{M}$ sodium thiosulfate was added. The mixture was vortexed for $2 \mathrm{~min}$ and left to repose for $30 \mathrm{~min}$ in order to remove the bacteria. Finally, $4 \mathrm{~mL}$ of broth culture was added and the tubes were incubated at $37^{\circ} \mathrm{C}$ for $24 \mathrm{~h}$ and agitated at $80 \mathrm{rpm}$. The bacterial number was determined as above indicated.

All assays were performed in triplicate and the results averaged. ANOVA followed by Tukey test were conducted as statistical analyses at a confidence level of $95 \%(p<0.05)$.

\section{In-vitro biocompatibility assays: cell adhesion and proliferation}

MDCK and VERO cells were cultured in Dulbecco's Modified Eagle Medium (DMEM) supplemented with $10 \%$ fetal bovine serum, $1 \%$ penicillin/streptomycin and 2 $\mathrm{mM}$ L-glutamine at $37^{\circ} \mathrm{C}$ in a humidified atmosphere with $5 \% \mathrm{CO}_{2}$ and $95 \%$ air. The culture medium was changed every two days and, for sub-culture, cell monolayers were rinsed with phosphate buffered saline (PBS) and detached by incubation with trypsinEDTA $(0.25 \%)$ at $37^{\circ} \mathrm{C}$ for $2-5 \mathrm{~min}$. Cell concentration was determined by counting 
with a Neubauer chamber and employing 4\% trypan-blue as dye vital. Detached cells with viability $\geq 95 \%$ were used for biocompatibility assays.

Square pieces $\left(10 \times 10 \times 0.1 \mathrm{~mm}^{3}\right)$ of both unloaded and drug-loaded PLA electrospun microfibers were cut to perform biocompatibility assays. These pieces were placed into the wells of a multi-well culture plate and sterilized by UV-radiation in a laminar flux cabinet for 15 min. To fix the samples in the well, a small drop of silicone (Silbione ${ }^{\circledR}$ MED ADH 4300 RTV, Bluestar Silicones France SAS, Lyon, France) was used as the adhesive. Samples were incubated in $1 \mathrm{~mL}$ of the culture medium under culture conditions for $30 \mathrm{~min}$ to equilibrate the material. Finally, the medium was aspired and the material was evaluated for cell adhesion and proliferation by exposing cells to direct contact with the material surface.

To assess cell adhesion, aliquots of $50-100 \mu \mathrm{L}$ containing $5 \times 10^{4}$ cells were seeded in the wells containing the electrospun scaffolds. The plate was incubated in culture conditions for $30 \mathrm{~min}$ to allow cell attachment to the material surface. Then, $1 \mathrm{~mL}$ of the culture medium was added to each well and the plate was incubated for another $24 \mathrm{~h}$. Finally, cell viability was determined by the MTT assay. Unloaded PLA scaffolds and samples loaded with $3 \mathrm{w} / \mathrm{v}-\%$ of TCS were used as positive controls and negative controls, respectively.

Cell proliferation was evaluated by a similar procedure to the adhesion assay, but the aliquot of 50-100 $\mu \mathrm{L}$ contained only $2 \times 10^{4}$ cells and the cultures were maintained for 7 days to allow cell growth and adequate cell confluence in the well. The medium was renewed every two days. Finally, cell viability was determined by the MTT assay.

Each sample was evaluated using five replicates and the results were averaged and graphically represented. The statistical analysis was performed by one-way ANOVA to 
compare the means of all groups; Tukey test was then applied to determine a statistically significant difference between two studied groups. The tests were performed with a confidence level of $95 \%(p<0.05)$.

\section{RESULTS AND DISCUSSION}

\section{Morphology of PLA multifunctional electrospun scaffolds}

The success of electrospinning process requires strict control of the operational parameters of each polymer (e.g., strength of the applied electrical field, tip-collector distance, flow rate) and solution properties (e.g., viscosity, surface-tension, dielectric constant, volatility, concentration). ${ }^{64,65}$ Selection of an appropriate solvent system probably becomes one of the most crucial points, especially when compounds of highly different characteristics (e.g. polylactides samples and the above selected drugs) must be electrospun. ${ }^{66}$ Note, for example, the large difference between reported Hildebrand parameters for $\operatorname{PLA}^{67}$ (i.e., $\left.9.87\left(\mathrm{cal} / \mathrm{cm}^{3}\right)^{0.5}\right)$ and $\operatorname{TCS}^{68}$ (i.e., $\left.14.38\left(\mathrm{cal} / \mathrm{cm}^{3}\right)^{0.5}\right)$. In addition, a relatively high polymer concentration is required to avoid formation of drops or beads ${ }^{49}$ and obtain continuous fibers in a micrometer scale, which appears more appropriate for a sustained drug release. These factors focused us to select a chloroform:acetone:dimethylsulfoxide mixture with a $6: 3: 1 \mathrm{v} / \mathrm{v} / \mathrm{v}$ ratio; specifically, the two first solvents were appropriate to obtain PLA electrospun microfibers, ${ }^{34}$ whereas the third solvent was essential to allow dissolution of the three selected drugs (TCS, CUM and KTP).

With regard to operational parameters, the selection of the spinning voltage (15 kV) was essential to ensure the formation of continuous and regular fibers and a minimum amount of beads. The distance between the target and the syringe tip was kept close to $12.5 \mathrm{~cm}$, and the flow rate was found to be drastically affected by the viscosity of the 
final solution. Thus, a flow rate of $10 \mathrm{~mL} / \mathrm{h}$ was chosen except when the three drugs dissolved simultaneously. In this case, it was necessary to reduce the flow rate to 5 $\mathrm{mL} / \mathrm{h}$ due to increased viscosity of the final solution.

Figure 2 shows low magnification SEM images of electrospun fibers obtained under the selected conditions for the different PLA grades and loaded drugs (in particular, single, binary and ternary drug-loaded scaffolds with CUM as the common drug). Analysis of these images revealed that fibers always had a unimodal Gaussian diameter distribution (Figure 3) with average diameters between $1.7 \mu \mathrm{m}$ and $3.8 \mu \mathrm{m}$ as summarized in Table 2. The observed variations in the diameter size can be summarized as follows: a) Microfibers prepared from the more stereoregular PLA 4032D sample always had smaller diameters than determined for PLA 2002D compared to fibers with a similar drug load; b) incorporation of CUM gave rise to a significant diameter increase (e.g. from 1.86 to $3.85 \mathrm{~nm}$ and from 1.66 to $2.14 \mathrm{~nm}$ for single drug-loaded PLA2002D and PLA 4032D samples, respectively), which seemed more significant when the more amorphous PLA grade was employed; c) binary drug-loaded samples showed a diameter decrease compared to single drug-loaded fibers, with the effect being less pronounce upon addition of TCS. Note, , in addition, that the percentage of loaded TCS was higher than that of KTP (i.e. $3 \mathrm{w} / \mathrm{v}-\%$ as opposed to $1 \mathrm{w} / \mathrm{v}-\%$ ), and d) the diameter of ternary drug-loaded samples increased compared to unloaded samples, as above indicated, but the trend was not clear since flow rate conditions were changed. In summary, the presence of drugs modified the physicochemical characteristics of the dissolution (e.g. viscosity was seriously affected in ternary TCS/KTP/CUM loaded mixtures in such a way that the flow rate had to be modified) and influenced the morphology of electrospun samples significantly even when processed under the same 
set of operational parameters. The obtained results suplement those previously described in the single loaded systems given in Table 1.

\section{[FIGURE 2]}

\section{[TABLE2]}

\section{[FIGURE 3]}

Texture of microfibers was slightly different depending on the loaded drugs as shown in the high magnification SEM micrographs of Figure 4. In general, microfibers had a porous structure as it is also commonly observed for unloaded PLA electrospun fibers. ${ }^{49}$ The presence of longitudinal striations was also usual in most of the prepared samples (Fig. 4, see red arrows). Surface became smoother when TCS was loaded since pores were less defined in the ternary drug loaded systems (Figures $4 \mathrm{~g}$ and $4 \mathrm{~h}$ ) and even difficult to detect in the binary drug-loaded fibers (Figure 4c and 4d). CUM loaded samples were also characterized by the presence of embedded crystals (withe arrows), which highlighted the difficulty of $p$-coumaric molecules to mix with the PLA matrix. Nevertheless, these crystals were hardly detected in the ternary drug-loaded systems although their fibers usually had the lowest diameter values. This may be an indication of improved mixing with PLA in the presence of the other two drugs (TCS and KTP).

\section{[FIGURE 4]}

\section{FTIR analysis of electrospun drug loaded samples}

PLA is a semicrystalline polymer that exhibits polymorphism, with different crystalline arrangements dependent on the crystallization conditions having been described. ${ }^{30,35}$ Usually, the polymer crystallizes in a $10_{7}$ helical conformation that gives rise to the so- 
called $\alpha-,{ }^{69-71} \alpha^{\prime}-{ }^{72}$ and $\alpha{ }^{\prime}{ }_{-}{ }^{73}$ forms and the $\varepsilon$-crystals ${ }^{74}$ when the polymer is complexed with solvents like dimethylformamide. Furthermore, PLA can adopt a $3_{2}$ molecular conformation as reported for $\beta^{75,76}$ and $\gamma^{77}$ structures prepared by stretching or epitaxial crystallization. Nevertheless, PLA hardly crystallizes under usual processing conditions, and therefore no crystallization peaks are usually observed in DSC cooling traces from the melt or even during a subsequent heating run. Thus, commercial semicrystalline samples are obtained after subjecting samples to an annealing process which favors crystallization. It has been reported that the electrospinning technique facilitates molecular orientation; hence, the derived microfibers can be easily cold crystallized during a subsequent heating run. This final molecular orientation should depend on solution properties like viscosity, operational parameters (e.g. flow rate and applied voltage), diameter of electrospun fibers and even the presence of drugs that could act as nucleating agents. ${ }^{34}$

FTIR spectroscopy can give information on molecular conformation and crystallinity although interpretation is difficult for PLA due to its different molecular conformations and packing arrangements. Nevertheless, several observations can be made: a) The absorbance of the carbonyl band around $1753 \mathrm{~cm}^{-1}$ has a smaller correlation with conformational changes of the main chain. Hence, this band can be used as the reference band to correct absorbance fluctuations due to differences in scaffold thickness; ${ }^{78} \mathrm{~b}$ ) comparison between absorbance of bands at $1263 \mathrm{~cm}^{-1}(v(\mathrm{CH})+v(\mathrm{C}-\mathrm{O}-\mathrm{C})$ for a random conformation) and $1209 \mathrm{~cm}^{-1}\left(v_{\mathrm{as}}(\mathrm{C}-\mathrm{O}-\mathrm{C})+r_{\mathrm{as}}\left(\mathrm{CH}_{3}\right)\right.$ for a $10_{7}$ helical conformation) has been reported to be highly relevant because bands should decrease and increase, respectively, when molecules adopt the more ordered helical conformation; $\left.{ }^{79} \mathrm{c}\right)$ relative intensities between bands at $1387 \mathrm{~cm}^{-1}\left(\delta_{\mathrm{s}}\left(\mathrm{CH}_{3}\right)\right.$, amorphous form) and $1360 \mathrm{~cm}^{-1}\left(\delta(\mathrm{CH})\right.$, semicrystalline form) and bands at $1134 \mathrm{~cm}^{-1}\left(r_{\mathrm{s}}\left(\mathrm{CH}_{3}\right)\right)$ 
and $1092 \mathrm{~cm}^{-1}\left(v_{\text {as }}(\mathrm{C}-\mathrm{O}-\mathrm{C})\right)$ changed upon annealing of samples (i.e. when crystallinity increased). Specifically, the relative intensity of bands at $1360 \mathrm{~cm}^{-1}$ and $1134 \mathrm{~cm}^{-1}$ was increased; ${ }^{80}$ and d) the $921 \mathrm{~cm}^{-1}$ absorption band is characteristic of the $\alpha$-form and corresponds to the coupling of $\mathrm{C}-\mathrm{C}$ backbone with $\mathrm{CH}_{3}$ rocking. ${ }^{81}$

Figure 5 compares the FTIR spectra $\left(1800-900 \mathrm{~cm}^{-1}\right)$ of the two unloaded PLA electrospun samples and the PLA 2002D sample loaded with the different combinations of drugs. No significant differences (not shown) were detected between spectra of samples from the two PLA matrices independently of the loaded drugs. Therefore, the difference in stereoregularity (i.e. from 2 to $4.2 w t-\%$ of D-lactide) was smaller than spectral sensitivity to chain randomness. On the contrary, spectra of both PLA 2002D and PLA 4032D (not shown) samples showed significant changes with respect to the above b-d points which clearly suggested an increase of crystallinity and the ratio of the $10_{7}$ helical conformation when, for example, PLA 2002D fibers were simultaneously loaded with different drugs (i.e. a decrease of $1263 \mathrm{~cm}^{-1}$ band and an increase of 1360 $\mathrm{cm}^{-1} 1209,1134$ and $921 \mathrm{~cm}^{-1}$ bands were observed for all loaded samples except the single CUM loaded sample).

\section{[FIGURE 5]}

FTIR spectra were sufficiently sensitive to detect the presence of drugs despite the small amount loaded. Basically, multiple peaks were observed in the $1670-1470 \mathrm{~cm}^{-1}$ range where bands associated with carbonyl groups and aromatic rings should appear. These rings were common for the three loaded drugs (Figure 1), and consequently additional signals detected in the spectra of drug-loaded scaffolds were always quite similar (i.e. peaks inside the dashed ellipsoids drawn in Figure 5).

\section{Thermal analysis of drug-loaded electrospun samples}


The slight difference in the D-lactide content (i.e. $4.2 w t-\%$ compared to $2.0 w t-\%$ ) affected thermal properties significantly, as depicted in Table 3 for the commercial pellet samples, which were expressly subjected to an annealing process to increase crystallinity. DSC heating traces of the corresponding electrospun scaffolds (Figures 6a and 6b) revealed again differences between the two PLA grades and also interesting consequences of the different processing methods. It should be pointed out that after electrospinning samples became practically amorphous but could be easily cold crystallized during a subsequent heating run, reaching typical crystallinity values of commercial annealed samples. A cold crystallization peak was hardly observed in the heating run of samples cooled from the melt state (i.e. not subjected to a specific annealing treatment), as also previously reported. ${ }^{82,83}$ Therefore, the capability of the electrospinning technique to render highly aligned and oriented molecules able to easily cold crystallize has been postulated by different authors. ${ }^{34,82}$

\section{[TABLE 3]}

\section{[FIGURE 6]}

DSC heating runs of drug-loaded samples are more complex, especially those of ternary drug-loaded systems (Figures 6c and 6d). The main thermal characteristics deduced from the loaded scaffolds (summarized in Table 3) allow the following general remarks to be made:

a) The glass transition temperature decreases compared to that observed for the corresponding unloaded scaffolds, suggesting a plasticizing effect caused by the incorporation of the small drug molecules. In addition, the enthalpic relaxation peak tends to be supressed, in contrast with unloaded samples. Therefore, the compact arrangement characteristic of an equilibrium condition is less favored. 
b) The melting peak temperature decreases dramatically compared to the value of unloaded scaffolds. Furthermore, this decrease is more and less significant for ternary and single drug-loaded scaffolds, respectively. In addition, multiple peaks could be observed for the more complex loaded systems. These features suggest that drugs can be partially incorporated into the crystalline structure and even lead to different degrees of perfection. It should be pointed out that the melting peaks could only be associated with the PLA polymer matrix because the melting temperatures of TCS and KTP were lower $\left(55-57{ }^{\circ} \mathrm{C}\right.$ and $93-96{ }^{\circ} \mathrm{C}$, respectively), whereas $p$-coumaric acid melted at a clearly higher temperature (i.e. $208-217^{\circ} \mathrm{C}$ ).

c) Binary and ternary drug-loaded systems become highly crystalline after the electrospinning process. Note the reduced cold crystallization enthalpy and the high melting enthalpy (i.e. the relatively high $\Delta H_{m}-\Delta H_{c}$ values). The degrees of crystallinity are clearly higher than determined from unloaded samples, suggesting a nucleating effect of incorporated drugs. This effect is more pronounced when the more regular PLA 4032D sample is used. ${ }^{84}$ Logically, all studied samples showed a degree of crystallinity after cold crystallization slightly lower than determined for the commercial annealed samples. The temperature of the cold crystallization peak tends to diminish for drug-loaded samples, suggesting again a nucleating effect of drugs.

\section{Drug release from binary and ternary drug-loaded PLA electrospun scaffolds}

Drug release from electrospun fibers in a given medium is intimately related to their morphology and crystallinity and to possible intermolecular interactions between drugs and the polymer matrix. Therefore, a quantitative release study was performed considering both PLA 2002D and PLA 4032D matrices and single, binary and ternary 
drug-loaded systems. We selected a phosphate buffered saline (PBS) supplemented with ethanol to facilitate the delivery of highly hydrophobic molecules such as TCS, KTP and CUM and avoid the establishment of equilibrium conditions that typically limit their release when only PBS is employed. ${ }^{33}$ Specifically, Figure 7 points out this problem for all loaded samples since the release percentage was always lower than $10 \%$. Logically, drug release was enhanced by increasing the EtOH ratio, being a fast delivery with a high release percentage (i.e. between $60 \%$ and 90\%) found for the PBS:EtOH 3:7 $v / v$ mixture. Experiments performed using a standard medium containing serum revealed an enhanced release with respect to PBS. Nevertheless, this release was clearly lower than determined for PBS:EtOH 3:7 v/v since diffusion of aqueous serum within the microfibers was no possible. Therefore, results obtained with the PBS:EtOH may be useful to better appreciate the effect of changing matrix characteristics and load system.

Figures $7 \mathrm{a}$ and $7 \mathrm{~b}$ show the release profile of CUM from the single drug-loaded PLA 2002D and PLA 4032D scaffolds in PBS:EtOH 3:7 v/v medium, respectively. It can be observed that a higher release percentage was attained from the less stereoregular PLA matrix (i.e. $80 \%$ compared to $60 \%$ ), indicating that CUM was better retained in the presence of polymer crystalline domains. In any case, the release of CUM was very fast and reached values of $60-50 \%$ after only one hour of exposure to the medium.

\section{[FIGURE 7]}

Figures $7 \mathrm{c}-7 \mathrm{~h}$ show the release profiles of TCS, KTP and CUM in PBS:EtOH 3:7 v/v medium from the binary and ternary drug-loaded systems. The following observations can be made: a) The release profiles for a given scaffold are similar for the three dugs independently of the PLA grade and the kind of system (binary or ternary); b) the 
maximum release percentage is always greater from PLA 2002D scaffolds than from the corresponding PLA 4032D scaffolds; c) release percentages increase slightly when more drugs are simultaneously loaded in PLA 4032D scaffolds (i.e. $60 \%, 60-70 \%$ and $80 \%$ for CUM in single, binary and ternary drug-loaded scaffolds, respectively), whereas percentages remain practically constant for PLA 2002D scaffolds. A slight synergic effect that increased the release seems to exist in complex systems and matrices that had higher encapsulation efficiency (e.g. PLA 4032D). This is interesting since it suggests that binary and ternary drug-loaded scaffolds have greater availability for their local action in the host tissue.

Release rates can be quantitatively compared considering postulated theoretical kinetic models in order to fit the experimental release profiles. Release generally occurs in two different steps, with the fast release initially observed (0-60\%) being well-described by the Higuchi equation:

$$
\mathrm{M}_{\mathrm{t}} / \mathrm{M}_{0}=k_{H} \mathrm{t}^{(1 / 2)} \quad\left(0 \leq M_{t} / M_{0} \leq 0.6\right)
$$

where $k_{H}$ is the Higuchi release constant, $M_{t}$ is the percentage of drug released at time $t$ and $M_{0}$ is the drug equilibrium percentage (considered as the maximum drug percentage). ${ }^{85,86}$ This model wa basically conceived for planar systems, but was then extended to different geometrics and porous systems.

Table 4 summarizes the values of $k_{H}$ determined for CUM from the loaded scaffolds. The results show small differences in the release rate but no specific trend linked to the degree of crystallinity, fiber diameter and complexity of the system (single, binary or ternary) can be derived, probably due to the multiple factors with different impact on molecular diffusion that are involved.

\section{[TABLE 4]}




\section{Antibacterial properties of single, binary and ternary CUM loaded electrospun scaffolds}

Bacterial growth curves for E. coli (Figures $8 \mathrm{a}$ and $8 \mathrm{~b}$ ) and M. luteus (Figures $8 \mathrm{c}$ and 8d) in the presence of unloaded and single, binary and ternary drug-loaded scaffolds of PLA 2002D and PLA 4032D were evaluated as an indication of the bactericide activity of loaded matrices.

\section{[FIGURE 8]}

Results clearly indicate that bacterial growth was inhibited for both binary and ternary TCS loaded scaffolds. This is a consequence of the well-known ability of TCS to block the active site of the enoyl-acyl carrier protein reductase enzyme, which is essential in the synthesis of fatty acids in bacteria. ${ }^{87}$ Thus, after 24 hours of culture, E. coli and $M$. luteus bacterial growths were $8-10 \%$ and $10-12 \%$ of the corresponding growths determined for the positive control, respectively. Curves were essentially independent of the polymer matrix and the additional incorporation of CUM and KTP. It seems that sufficient release was achieved by the high TCS content of scaffolds (i.e. $3 w / v-\%$ ) to inhibit bacterial growth. Also, this effect could not be improved by the presence of the other two drugs and was not influenced by morphology and crystallinity changes of electrospun scaffolds.

Figure 8 also shows typical bacterial growth curves for single CUM loaded scaffolds. Thus, after an initial lag phase (4-5 hours), an exponential phase associated with binary fission was observed during which Gram-negative and Gram-positive bacterial growth stopped at a value close to $90 \%$ with respect to that found for the positive control. More interestingly, binary KTP/CUM loaded scaffolds showed moderate inhibition that was slightly dependent on the PLA grade and the type of bacteria. Specifically, growth 
percentages decreased compared to the positive control to $40 \%$ and $50 \%$ for Gramnegative bacteria grown on matrices based on PLA 2002D and PLA 4032D, respectively, and to $50 \%$ and $60 \%$ for Gram-positive bacteria grown on matrices based on PLA 2002D and PLA 4032D, respectively. From these results two conclusions can be drawn: a) KTP has a bacteriostatic effect with a not yet fully clarified mechanism, ${ }^{88,89}$ and b) the less stereoregular PLA matrix has a higher inhibition effect, in agreement with the enhanced drug release (Figures 8c and 8d).

Bactericide activity was also evaluated by quantification of bacterial adhesion, as shown in Figure 9. Single CUM loaded scaffolds had a similar percentage of bacterial adhesion to the positive control, as expected from the bacterial growth results. In the same way, practically complete inhibition of bacterial adhesion was found for TCS/CUM and TCS/KTP/CUM loaded scaffolds. Intermediate adhesion values were obtained for binary KTP/CUM loaded scaffolds, with significant differences again being observed depending on the PLA grade. Thus, adhesions of $40 \%$ and $70 \%$ were determined for PLA 2002D (Figure 9a) and PLA 4032D (Figure 9b) scaffolds. The higher percentage found for the latter is in agreement with the differences in the release and bacterial growth. Adhesion results were similar for both Gram-negative and Gram-positive bacteria.

\section{[FIGURE 9]}

\section{Cell viability of single, binary and ternary CUM loaded electrospun scaffolds}

Figure 10 illustrates cell adhesion and proliferation behavior of two epithelial cell lines (MDCK and VERO) in loaded PLA 2002D and PLA 4032D electrospun scaffolds. A good cell response was expected for CUM and KTP according to their antioxidant and anti-inflammatory activity, respectively. MDCK and VERO cell lines were selected for 
their epithelial morphology and typical adherent growth which leads to formation of cell monolayers highly sensitive to cell damage due to their flake detachment from the culture plate.

\section{[FIGURE 10]}

Scaffolds loaded with $3 w / v-\%$ of TCS were used as negative controls since this concentration was previously found to be cytotoxic for loaded PLA scaffolds. ${ }^{34}$ Cell adhesion on these scaffolds decreased to $20-30 \%$ compared to unloaded PLA scaffolds (positive control) after $24 \mathrm{~h}$ of culture. Note that this significant difference $(p<0.001)$ was independent of the PLA grade (Figures 10a and 10b). It is highly interesting that incorporation of CUM reduced cell damage caused by TCS and favored cell viability. Thus, cell adhesion on binary TCS/CUM loaded scaffolds was increased by ca. $30 \%$ with respect to the negative control. Anti-inflammatory KTP had a similar, additive effect. In this way, cell adhesion on ternary TCS/KTP/CUM loaded scaffolds clearly increased and reached the same values as positive unloaded scaffolds and also as single drug-loaded PLA scaffolds (Figures 10a and 10b).

Adhered cells kept their proliferative activity and ultimately were able to colonize the material, forming a monolayer tissue. Figures $10 \mathrm{c}$ and $10 \mathrm{~d}$ show the quantification of cell growth, which was clearly related to the previous cell adhesion event. The cytotoxic effect of TCS can be reverted by the renewal of culture medium. Thus, cell viability increased, as demonstrated by values of $40 \%$ and $50 \%$ determined with respect to the unloaded scaffolds after 7 days of culture, which were higher that the above adhesion percentages. Nevertheless, viability was still significantly lower $(p<0.01)$ than determined for the control. Again, positive effects on cell proliferation $(p>0.95)$ were found for binary TCS/CUM loaded scaffolds compared to the negative TCS loaded 
control, resulting in an increase in cell viability up to $80 \%$. This represents an increase close to $30 \%$ with respect to the viable cells measured in single TCS loaded scaffolds. Cell proliferation in ternary TCS/KTP/CUM loaded scaffolds was similar to that of positive controls, as expected from the cell adhesion results, demonstrating that cell damage caused by TCS could be neutralized by the positive effect on cell viability caused by the incorporation of CUM and KTP. Finally, it should be indicated that no significant differences were observed between scaffolds prepared from the two PLA grades despite slight differences in drug release.

\section{CONCLUSIONS}

Bactericide, anti-inflammatory and antioxidant drugs like triclosan, ketoprofen and $p$ coumaric acid, respectively, could be simultaneously loaded into PLA microfibers by the electrospinning technique. Porous and continuous microfibers with a unimodal diameter distribution could be prepared from a $10 \mathrm{w} / \mathrm{v}-\%$ solution of PLA in a chloroform:acetone:dimethylsulfoxide mixture and using electrospinning parameters of $15 \mathrm{kV}, 12.5 \mathrm{~cm}$ and $5-10 \mathrm{~mL} / \mathrm{h}$ for voltage, tip-collector distance and flow rate, respectively.

Electrospun scaffolds had highly variable crystallinity which depended slightly on the PLA grade (at least when D-lactide content varied only from 4.2 to $2.0 \mathrm{wt}-\%$ ) and strongly on the incorporated drugs. Thus, drugs seemed to produce a nucleating effect that, in some cases, led to crystallization levels like those of commercial annealed samples even for binary drug-loaded systems. Drug-loaded scaffolds also showed a decrease in the glass transition temperature that favored molecular diffusion processes and a decrease in the melting temperature as a consequence of incorporation of drugs in amorphous and crystalline phases, respectively. 
The three drugs were released in a similar and fast way from a given scaffold (i.e. for a selected PLA matrix and a single, binary or ternary drug-loaded system) in a PBS:ethanol medium that mimics a typical serum supplemented PBS medium. In all cases, a significant amount of drug was retained inside PLA microfibers, especially the more stereoregular polymer. The entrapping efficiency of PLA was limited and the release of a specific drug seemed to increase with the complexity of the system (i.e. from single to ternary drug-loaded scaffolds), suggesting a synergic effect. New

multifunctional scaffolds appear highly interesting since, besides imparting their expected and specific properties (i.e. antioxidant and anti-inflammatory), KTP and CUM can neutralize the cytotoxic effect caused by a moderate/high triclosan load. In summary, multifunctional PLA scaffolds with both high cell viability and protection against microorganisms can be easily prepared by the electrospinning technique.

\section{Acknowledgments}

Authors are in debt to supports from MINECO and FEDER (MAT2012-36205) and the Generalitat de Catalunya (2009SGR1208). 


\section{REFERENCES}

1. Sahay, R.; Kumar, P. S.; Sridhar, R.; Sundaramurthy, J; Venugopal, J.; Mhaisalkar, S. G.; Ramakrishna, S. J. Mater. Chem. 2012, 22, 12953.

2. Nair, L. S.; Laurencin, C. T. Prog. Polym. Sci. 2007, 32, 762.

3. Ji, Y.; Ghosh, K.; Shu, X. Z.; Li, B.; Sokolov, J. C.; Prestwich, G. D.; Clark, R. A.; Rafailovich, M. H. Biomaterials 2006, 27, 3782.

4. Ma, P. X. Mater. Today 2004, 7, 30.

5. Dhandayuthapani, B.; Yoshida, Y.; Maekawa, T.; Kumar, D. S. Inter J. Polym. Sci. 2011, 2011, 1 .

6. Ma, Z. W.; Kotaki, M.; Inai, R.; Ramakrishna, S. Tissue Eng. 2005, 11, 101.

7. Bhattarai, S. R.; Bhattarai, N.; Yi, H. K.; Hwang, P. H.; Cha, D. I.; Kim, H. Y. Biomaterials 2004, 25, 2595.

8. Vasita, R.; Katti, D. S. Int. J. Nanomedicine 2006, 1, 15.

9. Geng, X.; Kwon, O. H. J. Jang, Biomaterials 2005, 26, 5427.

10. Um, I. C.; Fang, D.; Hsiao, B. S.; Okamoto, A.; Chu, B. Biomacromolecules 2004, $5,1428$.

11. Jin, H. J.; Chen, J. S.; Karageorgiou, V.; Altman, G. H.; Kaplan, D.L. Biomaterials 2004, 25, 1039.

12. Yang, F.; Murugan, R.; Wang, S.; Ramakrishna, S. Biomaterials 2005, 26, 2603.

13. Riboldi, S. A.; Sampaolesi, M.; Neuenschwander, P.; Cossu, G.; Mantero, S. Biomaterials 2005, 26, 4606.

14. Li, W. J.; Danielson, K. G.; Alexander, P. G.; Tuan, R. S. J. Biomed. Mater. Res. A 2003, 67A, 1105.

15. Uematsu, K.; Hattori, K.; Ishimoto, Y.; Yamauchi, J.; Habata, T.; Takakura, Y.; Ohgushi, H.; Fukuchi, T.; Sato, M. Biomaterials 2005, 26, 4273. 
16. Kenawy, E. R.; Bowlin, G. L.; Mansfield, K.; Layman, J.; Simpson, D. G.; Sanders, E. H.; Wnek, G. E. J. Control Release 2002, 81, 57.

17. Mo, X. M.; Xu, C. Y.; Kotaki, M.; Ramakrishna, S. Biomaterials 2004, 25, 1883.

18. Verreck, G.; Chun, I.; Rosenblatt, J.; Peeters, J.; Van Dijck, A.; Mensch, J.; Noppe, M.; Brewster, M. E. J. Control. Release 2003, 92, 349.

19. Llorens, E.; Armelin, E.; Pérez-Madrigal, M. M.; del Valle, L. J.; Alemán, C.; Puiggalí, J. Polymers 2013, 5, 1115.

20. Llorens, E.; Pérez-Madrigal, M. M.; Armelin, E.; del Valle, L. J.; Puiggalí, J.; Alemán, C. RSC Adv. 2014, 4, 15245.

21. Jacobsen, S. M.; Stickler, D. J.; Mobley, H. L. T.; Shirtliff, E. Clin. Microbiol. Rev. 2008, 21, 26.

22. Fuster, D.; Duch, J.; Soriano, A.; García, S.; Setoain, X.; Bori, G.; Rubí, S.; Rodríguez, D.; Doménech, B.; Piera, C.; Mensa, J.; Pons, F. Rev. Esp. Med. Nucl. Imagen. Mol. 2008, 27, 430.

23. Gao, Y.; Truong, Y. B.; Zhu, Y.; Kyratzis, I. L. J. Appl. Polym. Sci. 2014, 131, 40797.

24. Neeff, H. P.; von Dobschuetz E.; Sommer, O.; Hopt, U. T.; Drognitz, O. Transplant Int. 2008, 21, 1081.

25. Jassem, W.; Heaton, N. D. Kidney Int. 2004, 66, 514.

26. Suwantong, O.; Ruktanonchai, U.; Supaphol, P. J. Biomed. Mater. Res. A 2010, $94 A, 1216$.

27. Taepaiboon, P.; Rungsardthong, U.; Supaphol, P. Eur. J. Pharm. Biopharm. 2007, $67,387$.

28. Merrell, J. G.; McLaughlin, S. W.; Tie, L.; Laurencin, C. T.; Chen, A. F.; Nair, L. S. Clin. Exp. Pharmacol. Physiol. 2009, 36, 1149. 
29. Chuysinuan, P.; Chimnoi, N.; Techasakul, S.; Supaphol, P. Macromol. Chem. Phys. 2009, 210, 814 .

30. Llorens, E.; del Valle, L. J.; Díaz, A.; Casas, M.T.; Puiggalí, J. Macromol. Res. 2013, 21, 775 .

31. Abrigo, M.; McArthur, S. L.; Kingshott, P. Macromol. Biosci. 2014, 14, 772.

32. Cailloux, J.; Santana, O. O.; Franco-Urquiza, E.; Bou, J. J.; Carrasco, F.; Maspoch, M. L. J. Mater. Sci. 2014, 49, 4093.

33. Zurita, R.; Puiggali, J.; Rodriguez-Galan, A. Macromol. Biosci. 2006, 6, 58.

34. del Valle, L. J.; Camps, R.; Diaz, A.; Franco, L.; Rodriguez-Galan, A.; Puiggali, J. J. Polym. Res. 2011, 18, 1903.

35. Llorens, E.; del Valle, L. J.; Puiggalí, J. Macromol. Res. 2014, 22, 388.

36. Shah, P. P.; Desai, P. R.; Singh, M. J. Control. Release 2012, 158, 336.

37. Vueba, M. L.; Pina, M. E.; Veiga, F.; Sousa, J. J.; de Carvalho, L. A. E. B. Int. J. Pharm. 2006, 307, 56.

38. Li, D., Xia, Y. N. Adv. Mater. 2004, 16, 1151.

39. Kayaci, F.; Umu, O.C.O.; Tekinay T.; Uyar, T. J. Agric. Food Chem. 2013, 61, 3901.

40. Chen, L.; Bromberg, L.; Hatton, T. A.; Rutledge, G. C. Polymer 2008, 49, 1266.

41. Gliscinska, E.; Gutarowska, B.; Brycki, B.; Krucinska, I. J. Appl. Polym. Sci. 2013, $128,767$.

42. Liu, X.; Lin, T.; Gao, Y.; Xu, Z.; Huang, C.; Yao, G.; Jiang, L.; Tang, Y.; Wang, X. J. Biomed. Mater. Res. B 2012, 100, 1556.

43. Mei, Y.; Yao, C.; Fan, K.; Li, X. J. Membr. Sci. 2012, 417, 20.

44. Ren, X.; Kocer, H. B.; Worley, S. D.; Broughton, R. M.; Huang, T. S. J. Appl. Polym. Sci. 2013, 127, 3192. 
45. Spasova, M.; Manolova, N.; Paneva, D.; Rashkov, I. e-Polymers 2004, 4, 1.

46. Heunis, T.; Bshena, O.; Klumperman, B.; Dicks, L. Int. J. Mol. Sci. 2011, 12, 2158.

47. del Valle, L. J.; Roa, M.; Díaz, A.; Casas, M. T.; Puiggalí, J.; Rodríguez-Galán, A. J. Polym. Res. 2012, 19, 9792.

48. del Valle, L. J.; Díaz, A.; Royo, M.; Rodríguez-Galán, A.; Puiggalí, J. Express Polym. Lett. 2012, 6, 266.

49. Llorens, E.; del Valle, L. J.; Ferrán, R.; Rodríguez-Galán, A.; Puiggalí, J. J. Polym. Res. 2014, 21, 360 .

50. Fernandes, J. G.; Correia, D. M.; Botelho, G.; Padrão, J.; Dourado, F.; Ribeiro, C.; Lanceros-Méndez, S.; Sencadas, V. Polym. Test. 2014, 34, 64.

51. Yu, D. G.; Wang, X.; Li, X. Y.; Chian, W.; Li, Y.; Liao, Y. Z. Acta Biomaterialia 2013, 9, 5665.

52. Kenawy, E. R.; Abdel-Hay, F. I.; El-Newehy, M. H.; Wnek, G. E. Mat. Sci. and Eng. A-Struct. 2007, 459, 390.

53. Merrell, J. G.; McLaughlin, S. W.; Tie, L.; Laurencin, C. T.; Chen, A. F.; Nair, L. S. Clin. Exp. Pharmacol. Physiol. 2009, 36, 1149.

54. Vacanti, N. M.; Cheng, H.; Hill, P. S.; Guerreiro, J. D. T.; Dang, T. T.; Ma, M.; Watson, S.; Hwang, N. S.; Langer, R.; Anderson. D. G. Biomacromolecules 2012, $13,3031$.

55. Cantón, I.; Mckean, R.; Charnley, M.; Blackwood, K. A.; Fiorica, C.; Ryan, A. J.; MacNeil, S. Biotechnol. Bioeng. 2010, 105, 396.

56. Tammaro, L.; Russo, G.; Vittoria. V. Journal of Nanomaterials 2009, 2009, Article ID 238206. 
57. Ashammakhi, N.; Ndreu, A.; Piras, A. M.; Nikkola, L.; Sindelar, T.; Ylikauppila, H.; Harlin, A.; Gomes, M. E.; Neves, N. M.; Chiellini, E.; Chiellini, F.; Hasirci, V.; Redl, H.; Reis. R. L. Journal of Nanoscience and Nanotechnology 2006, 6, 2693.

58. Toncheva, A.; Paneva, D.; Manolova, N.; Rashkov, I. Macromol. Res. 2011, 19, 1310.

59. Parana, P.; Bandhitsing, T.; Thitiwongsawet, P. Thammasat International Journal of Science and Technology 2014, 19, 37.

60. Taepaiboon, P.; Rungsardthong, U.; Supaphol, P. Eur. J. Pharm. Biopharm. 2007, $67,387$.

61. Chuysinuan, P.; Chimnoi, N.; Techasakul, S.; Supaphol, P. Macromol. Chem. Phys. 2009, 210,814 .

62. Huang, Z-M.; He, C-L.; Yang, A.; Zhang, Y.; Han, X-J.; Yin, J.; Wu, Q. J. Biomed. Mater. Res-A 2006, 77A, 169.

63. Cailloux, J.; Santana, O. O.; Franco-Urquiza, E.; Bou, J. J.; Carrasco, F.; GamezPerez, J.; Maspoch, M. L. Express Polym. Lett. 2013, 7, 304.

64. Dhakate, S. R.; Singla, B.; Uppal, M.; Mathur, R. B. Adv. Mater. Lett. 2010, 1, 200.

65. Luong-Van, E.; Grondahl, L.; Chua, K. N.; Leong, K. W.; Nurcombe, V.; Cool, S. M. Biomaterials 2006, 27, 2042.

66. Buschle-Diller, G.; Cooper, J.; Xie, Z.; Wu, Y.; Waldrup, J.; Ren, X. Cellulose 2007, 14, 553.

67. Karst, D.; Yang, Y. J. Appl. Polym. Sci. 2005, 96, 416.

68. Aragón, D. M.; Chiappetta, D. A.; Degrossi, J.; Vargas, E. F.; Bregni, C.; Sosnik, A.; Martínez, F. Rev. Col. Cienc. Quím. Farm. 2008, 37, 241.

69. De Santis, P.; Kovacs, A. J. Biopolymers 1968, 6, 299. 
70. Alemán, C.; Lotz, B.; Puiggali, J. Macromolecules 2001, 34, 4795.

71. Sasaki, S.; Asakura, T. Macromolecules 2003, 36, 8385.

72. Zhang, J.; Tashiro, K.; Domb, A. J.; Tsuji, H. Macromol. Symp. 2006, 242, 274.

73. Marubayashi, H.; Akaishi, S.; Akasaka, S.; Asai, S.; Sumita, M. Macromolecules 2008, 41, 9192 .

74. Marubayashi, H.; Asai, S.; Sumita, M. Macromolecules 2012, 45, 1384.

75. Eling, B.; Gogolewski, S.; Pennings, A. J. Polymer 1982, 23, 1587.

76. Puiggali, J.; Ikada, Y.; Tsuji, H.; Cartier, L.; Okihara, T.; Lotz, B. Polymer 2000, 41,8921 .

77. Cartier, L.; Okihara, T.; Ikada, Y.; Tsuji, H.; Puiggali, J.; Lotz, B. Polymer 2000, 41, 8909 .

78. Fujiwara, T.; Miyamoto, M.; Kimura, Y.; Sakurai, S. Polymer 2001, 42, 1515.

79. Urayama, H.; Moon, S. I.; Kimura, Y. Macromol. Mater. Eng. 2003, 288, 137.

80. Ribeiro, C.; Sencadas, V.; Costa, C. M.; Ribelles, J. L. G.; Lanceros-Mendez, S. Sci. Technol. Adv. Mat. 2011, 12. 015001

81. Kang, S. O.; Hsu, S. L.; Stidham, H. D.; Smith, P. B.; Leugers, M. A.; Yang, X. Macromolecules 2001, 34, 4542.

82. Zeng, J.; Chen, X.; Liang, Q.; Xu, X.; Jing, X. Macromol. Biosci. 2004, 4, 1118.

83. Cho, T. Y.; Strobl, G. Polymer 2006, 47, 1036.

84. Sarasua, J. R.; Prud'homme, R. E.; Wisniewski, M.; Le Borgne, A.; Spassky, N. Macromolecules 1998, 31, 3895.

85. Higuchi, T. J. Pharm. Sci. 1963, 52, 1145.

86. Baker, R. W. John Wiley \& Sons, New York, USA, 1987.

87. Levy, C. W.; Roujeinikova, A.; Sedelnikova, S.; Stuitje, A. R.; Salabas, A. R.; Rice, D. W.; Rafferty, J. B. Nature 1999, 398, 383. 
88. Dastidar, S. G.; Ganguly, K.; Chaudhuri, K.; Chakrabarty, A. N. Int. J. Antimicrob. Ag. 2000, 14, 249.

89. Abbas, H. A.; Serry, F. M.; El-Masry, E. M. Asian J. Res. Pharm. Sci. 2012, 2, 66. 


\section{FIGURE CAPTIONS}

Figure 1. Chemical structures of polylactide (PLA 2002D and PLA 4032D), triclosan (TCS), p-coumaric acid (CUM) and ketoprofen (KTP).

Figure 2. Low magnification SEM micrographs of PLA 2002D + CUM (a), PLA 4032D + CUM (b), PLA 2002D + TCS/CUM (c), PLA 4032D + TCS/CUM (d), PLA 2002D + KTP/CUM (e), PLA 4032D + TCS/CUM (f), PLA 2002D + TCS/KTP/CUM (g) and PLA 4032D + TCS/KTP/CUM (h) samples.

Figure 3. Diameter distribution of PLA + CUM (a), PLA + KTP/CUM (b), PLA + TCS/CUM (c) and PLA + TCS/KTP/CUM (d) electrospun microfibers.

Figure 4. High magnification SEM micrographs of PLA 2002D + CUM (a), PLA 4032D + CUM (b), PLA 2002D + TCS/CUM (c), PLA 4032D + TCS/CUM (d), PLA 2002D + KTP/CUM (e), PLA 4032D + TCS/CUM (f), PLA 2002D + TCS/KTP/CUM (g) and PLA 4032D + TCS/KTP/CUM (h) samples. Dashed arrows point to longitudinal striations whereas CUM crystals are indicated by white arrows.

Figure 5. FTIR spectra $\left(1800-900 \mathrm{~cm}^{-1}\right.$ region) of PLA 2002D, PLA 4032D, PLA 2002D + CUM, PLA 2002D + TCS/CUM, PLA 2002D + KTP/CUM and PLA 2002D + TCS/KTP/CUM electrospun scaffolds. Wavenumbers of main peaks are labelled.

Figure 6. DSC heating runs $\left(20^{\circ} \mathrm{C} / \mathrm{min}\right)$ of PLA 2002D (a), PLA 4032D (b), PLA 2002D + TCS/KTP/CUM (c) and PLA 4032D + TCS/KTP/CUM (d) electrospun scaffolds. 
Figure 7. Release curves in PBS:EtOH (black symbols), PBS supplemented with serum (red symbols), PBS (blue symbols) media of CUM (a,b), TCS/CUM (c,d), KTP/CUM (e,f) TCS/KTP/CUM (g,h) loaded PLA 2002D (a,c,e,g) and PLA 4032D (b,d,f,h) electrospun scaffolds.

Figure 8. Relative growth of Escherichia coli $(\mathrm{a}, \mathrm{b})$ and Micrococcus luteus $(\mathrm{c}, \mathrm{d})$ on binary and ternary drug-loaded PLA 2002D (a,c) and PLA 4032D (b,d) electrospun scaffolds.

Figure 9. Escherichia coli (blue) and Micrococcus luteus (pink) adhesion on a polystyrene plate as positive control and single, binary and ternary drug-loaded PLA 2002D (a) and PLA 4032D (b) electrospun scaffolds $\left(^{*} p<0.05\right.$ vs. control, ANOVATukey test).

Figure 10. Adhesion (a,b) and proliferation (c,d) of MDCK (blue) and VERO (red) cells on a polystyrene plate as positive control and TCS, CUM, TCS/CUM, KTP/CUM and TCS/KTP/CUM PLA 2002D (a,b) and PLA 4032D (c,d) electrospun scaffolds $\left({ }^{\dagger} p<0.05 ;{ }^{\ddagger} p<0.01\right.$ vs. positive, ANOVA-Tukey test). 
Table 1. Electrospun of scaffolds loaded with active agents. ${ }^{\text {a }}$

\begin{tabular}{|c|c|c|c|}
\hline Electrospun Polymer & Solvent & Concentration & Active Agent \\
\hline \multicolumn{4}{|c|}{ Bactericide loaded systems } \\
\hline PCL/PLA & CF/acetone $2: 1 \mathrm{v} / \mathrm{v}$ & $10 w / v-\%$ & Triclosan $^{34}$ \\
\hline PLA & $\mathrm{CF} / \mathrm{DMF} 9: 1 \mathrm{v} / \mathrm{v}$ & $8 w / v-\%$ & Triclosan $^{39}$ \\
\hline $\mathrm{CA}$ & DMF & $3 w t-\%$ & Chlorhexidine ${ }^{40}$ \\
\hline PAN & DMSO & $15 w t-\%$ & $\mathrm{QACs}^{41}$ \\
\hline $\mathrm{CA} / \mathrm{PEU}$ & DMF/THF $50: 50 \mathrm{v} / \mathrm{v}$ & $20 / 10 w t-\%$ & PHMB ${ }^{42}$ \\
\hline PAN & DMF & $10 w / v-\%$ & PHMB $^{43}$ \\
\hline PAN & DMF & $10 w t-\%$ & N-Halamine ${ }^{44}$ \\
\hline PEO/Chitosan & $\mathrm{H}_{2} \mathrm{O} /$ Acetic acid & $3-4 w t-\%$ & $\mathrm{~K} 5 \mathrm{~N} 8 \mathrm{Q}^{45}$ \\
\hline PDLLA, PEO & DMF & $20-24 w t-\%$ & $\begin{array}{l}\text { Antibacterial } \\
\text { peptides }\end{array}$ \\
\hline PADAS & HFIP & $10 w t-\%$ & Chlorhexidine ${ }^{47}$ \\
\hline PLA/PCL & CF-acetone $2: 1 \mathrm{v} / \mathrm{v}$ & $10-2.5 w t-\%$ & Triclosan $^{48}$ \\
\hline PLA/PEG & DCM/DMF 70:30 v/v & $7-35 w t-\%$ & Triclosan ${ }^{49}$ \\
\hline $\mathrm{PHB} / \mathrm{PEO}$ & $\mathrm{DMF} / \mathrm{CF} \quad 80: 20 \mathrm{v} / \mathrm{v}$ & $10 w t-\%$ & Chlorhexidine $^{50}$ \\
\hline \multicolumn{4}{|c|}{ Anti-inflammatory loaded systems } \\
\hline PVP & DMAc/ethanol $1: 9 \mathrm{v} / \mathrm{v}$ & $10 w t-\%$ & Ketoprofen $^{51}$ \\
\hline EC (ethyl cellulose) & ethanol & $12.5 w t-\%$ & Ketoprofen ${ }^{38}$ \\
\hline PVA & Deionized water & $5 w t-\%$ & Ketoprofen ${ }^{52}$ \\
\hline PCL & 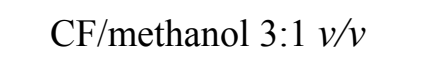 & $3-17 w t-\%$ & Curcumin $^{53}$ \\
\hline PCL & $\mathrm{CF} / \mathrm{DMF} 3: 1 \mathrm{v} / \mathrm{v}$ & $5.7 w t-\%$ & Dexamethasone 54 \\
\hline PLA & DCM/DMF 62.5:37.5 v/v & $5.7 w t-\%$ & Dexamethasone ${ }^{41}$ \\
\hline PLGA & DCM & $1-10 w t-\%$ & Ibuprofen ${ }^{55}$ \\
\hline PCL & acetone & $0.5-5 w t-\%$ & Diclofenac sodium $^{56}$ \\
\hline PAM14 & Ethanol or Acetic Acid & $2 w t-\%$ & Diclofenac sodium $^{57}$ \\
\hline PLA, PLA/PEG & DMF/DMSO $3: 1 w / w$ & $30 w t-\%$ & Diclofenac sodium $^{58}$ \\
\hline \multicolumn{4}{|c|}{ Antioxidant loaded systems } \\
\hline PCL & DCM/DMF $1: 1 \mathrm{v} / \mathrm{v}$ & $2.5-10 w t-\%$ & Resorcinol $^{59}$ \\
\hline $\mathrm{CA}$ & Acetone $/$ DMAc $2: 1 \mathrm{v} / \mathrm{v}$ & $5 w t-\%$ & Vitamin $E^{60}$ \\
\hline $\mathrm{CA}$ & Acetone $/$ DMAc $2: 1 \mathrm{v} / \mathrm{v}$ & $0.5 w t-\%$ & Vitamin $\mathrm{A}^{47}$ \\
\hline PLA & DMF/DMSO 9:1 v/v & $9.1 w t-\%$ & Vitamin B6 ${ }^{30}$ \\
\hline PLA & DMF/DMSO 9:1 v/v & $9.1 w t-\%$ & Polyphenols ${ }^{48}$ \\
\hline PCL & 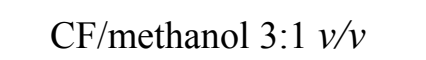 & $3-17 w t-\%$ & Curcumin 40 \\
\hline PLLA & $\mathrm{DCM} / \mathrm{DMF} 7: 3 \mathrm{v} / \mathrm{v}$ & $28.6 w t-\%$ & Gallic Acid $^{61}$ \\
\hline PCL & CF/ethanol 3:1 w/w & $4-10 w t-\%$ & Resveratrol ${ }^{62}$ \\
\hline
\end{tabular}

a PCL (poly(e-caprolactone)), PLA (polylactide), PDLLA (poly(D,L-lactide)), PEG (poly(ethylene glicol)), CA (cellulose acetate), PAN (polyacrylonitrile), PEU (poly (ester urea)), PEO (poly(ethylene oxide)), PADAS (poly(ester amide) derived from alanine, 1,12dodecanediol and sebacic acid units), QACs (N,N-didecyl-N,N-dimethylammonium chloride and bis-(3-aminopropyl)-dodecylamine), PHMB (polyhexamethylenebiguanide hydrochloride), K5N8Q (potassium 5-nitro-8-quinolinolate), DMF (N,N-dimethylformamide), DMSO (dimethyl sulfoxide), THF (tetrahydrifurane), HFIP (hexafluoroisopropanol), PHB (poly(hydroxybutyrate)), CF (Chloroform), DCM (dichloromethane). PAM14 (poly(maleic anhydride-alt-2-methoxyethyl vinyl ether)). DMAc (N,N-dimethylacetamide). 
Table 2. Diameters of unloaded and drug loaded electrospun PLA fibers.

\begin{tabular}{cc}
\hline Sample & Diameter $^{\mathbf{a}, \mathbf{b}}(\mu \mathrm{m})$ \\
\hline PLA 2002D & $1.86 \pm 0.06$ \\
PLA 4032D & $1.66 \pm 0.05$ \\
PLA 2002D + CUM & $3.85 \pm 0.01$ \\
PLA 4032D + CUM & $2.14 \pm 0.03$ \\
PLA 2002D + TCS/CUM & $3.23 \pm 0.01$ \\
PLA 4032D + TCS/CUM & $1.92 \pm 0.06$ \\
PLA 2002D + KTP/CUM & $2.28 \pm 0.01$ \\
PLA 4032D + KTP/CUM & $1.82 \pm 0.03$ \\
PLA 2002D + TCS/KTP/CUM & $2.54 \pm 0.01$ \\
PLA 4032D + TCS/KTP/CUM & $1.70 \pm 0.01$
\end{tabular}

${ }^{a}$ Fibers were obtained using same electrospinning operational parameters: applied voltage of $15 \mathrm{kV}$, tip-collector distance of $12.5 \mathrm{~cm}$ and flow rate of $10 \mathrm{~mL} / \mathrm{h}$ except for ternary drugloaded fibers that decreased to $5 \mathrm{~mL} / \mathrm{h}$.

${ }^{\mathrm{b}}$ Mean value \pm standard deviation. 
Table 3. Selected calorimetric data from the heating scan performed with the different PLA electrospun samples.

\begin{tabular}{|c|c|c|c|c|c|c|c|}
\hline Sample & $\begin{array}{c}T_{g} \\
\left({ }^{\circ} \mathbf{C}\right)\end{array}$ & $\begin{array}{c}T_{c} \\
\left({ }^{\circ} \mathrm{C}\right)\end{array}$ & $\begin{array}{l}\Delta H_{c}^{b} \\
(\mathrm{~J} / \mathrm{g})\end{array}$ & $\begin{array}{l}T_{m}{ }^{c} \\
\left({ }^{\circ} \mathrm{C}\right)\end{array}$ & $\begin{array}{c}\Delta H_{m}{ }^{b} \\
(\mathrm{~J} / \mathrm{g})\end{array}$ & $\begin{array}{c}\Delta H_{\mathrm{m}}-\Delta H_{c}^{b} \\
(\mathrm{~J} / \mathrm{g})\end{array}$ & $X_{c}^{d}$ \\
\hline PLA 2002D ${ }^{a}$ & 59.6 & - & - & 149.3 & 29.2 & 29.2 & 0.28 \\
\hline PLA 2002D & 59.3 & 106.0 & 18.5 & 146.4 & 26.1 & 7.6 & $0.07,0.25$ \\
\hline PLA 4032D ${ }^{a}$ & 69.3 & - & - & 167.0 & 35.0 & 35.0 & 0.33 \\
\hline PLA 4032D & 62.4 & 100.2 & 22.6 & 165.9 & 30.8 & 8.2 & $0.08,0.29$ \\
\hline PLA 2002D + CUM & 54.2 & 94.6 & 24.0 & 136.5 & 24.1 & 0.1 & $0.00 \cdot 0.27$ \\
\hline PLA 4032D + CUM & 55.0 & 75.1 & 24.5 & 156.3 & 31.7 & 7.2 & $0.07,0.30$ \\
\hline PLA 2002D + TCS/CUM & 48.6 & 92.7 & 6.1 & 132.2 & 21.5 & 15.4 & $0.16,0.22$ \\
\hline PLA 4032D + TCS/CUM & 44.1 & 65.9 & 10.2 & 147.2 & 28.9 & 18.7 & $0.19,0.27$ \\
\hline PLA 2002D + KTP/CUM & 43.5 & 60.0 & 5.2 & 112.9 & 28.1 & 22.9 & $0.22,0.27$ \\
\hline PLA 4032D + KTP/CUM & 44.2 & 52.2 & 3.8 & 138.9 & 28.2 & 24.4 & $0.25,0.29$ \\
\hline PLA $2002 \mathrm{D}+\mathrm{TCS} / \mathrm{KTP} / \mathrm{CUM}$ & 43.0 & 93.1 & 2.6 & 122.8 & 13.5 & 10.9 & $0.10,0.13$ \\
\hline PLA $4032 \mathrm{D}+\mathrm{TCS} / \mathrm{KTP} / \mathrm{CUM}$ & 43.0 & - & - & $122.7, \mathbf{1 2 6 . 1}^{\mathrm{e}}$ & 18.6 & 18.6 & 0.18 \\
\hline
\end{tabular}

${ }^{a}$ Data obtained from commercial pellet samples.

${ }^{b}$ Values have been rescaled considering the theoretical content of TCS (i.e. $\left.3 w / v-\%\right)$, KTP (i.e. 1 w/v- $\%$ ) and CUM (i.e. 1 w/v- $\%$ ).

${ }^{\mathrm{c}}$ Shoulders are rather frequent at a lower temperature than that indicated for the predominant melting peak.

${ }^{\mathrm{d}}$ Determined by considering an estimated melting enthalpy of $106 \mathrm{~J} / \mathrm{g}$ for a $100 \%$ crystalline sample. ${ }^{83,84}$ Left and right values correspond to crystallinities deduced for the as electrospun material (i.e. considering $\Delta H_{m}-\Delta H_{c}$ as the enthalpy associated to crystalline phase of the electrospun sample) and those attained after cold crystallization (i.e. considering $\Delta H_{m}$ as the enthalpy associated to the final crystalline phase), respectively.

${ }^{\mathrm{e}}$ Two predominant peaks were clearly detected. The most intense is in this case indicated by bold characters. 
Table 4. Higuchi kinetic constant and correlation factor for the first part (0-60\%) of the CUM release from the different loaded scaffolds.

\begin{tabular}{ccc}
\hline Sample & $\boldsymbol{k}_{\boldsymbol{H}}\left(\mathbf{h}^{\mathbf{- 0 . 5}}\right)$ & $\boldsymbol{r}$ \\
\hline PLA 2002D + CUM & 0.76 & 0.989 \\
PLA 4032D + CUM & 0.69 & 0.990 \\
PLA 2002D + TCS/CUM & 0.57 & 0.990 \\
PLA 4032D + TCS/CUM & 0.72 & 0.986 \\
PLA 2002D + KTP/CUM & 1.07 & 0.991 \\
PLA 4032D + KTP/CUM & 0.89 & 0.982 \\
PLA 2002D + TCS/KTP/CUM & 0.41 & 0.985 \\
PLA 4032D + TCS/KTP/CUM & 0.67 & 0.998 \\
\hline
\end{tabular}




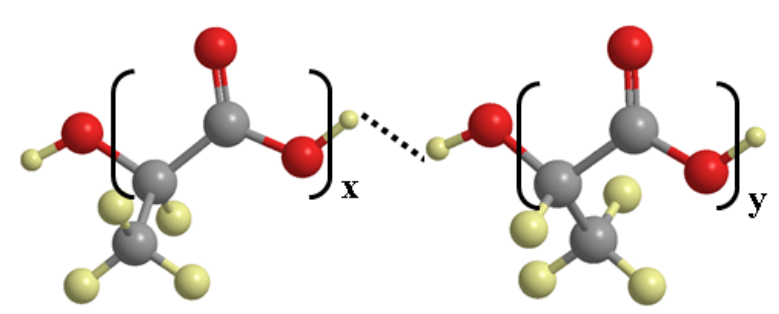

(D, L)-PLA

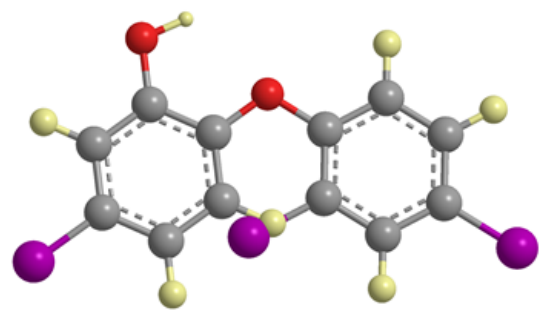

TCS

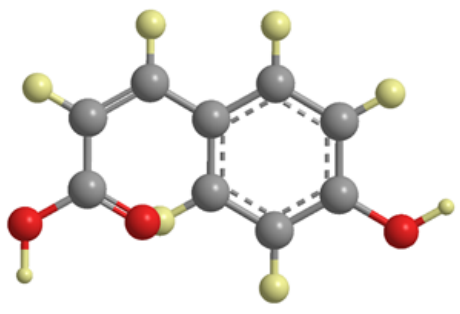

CUM

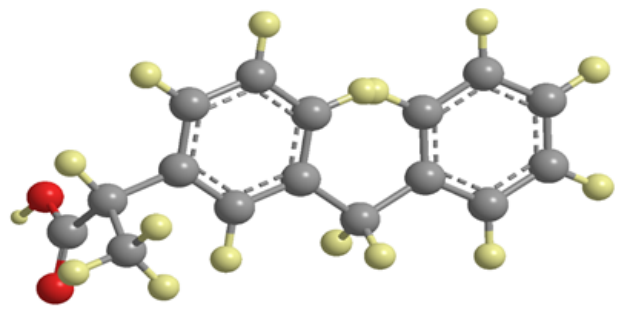

KTP
FIGURE 1

Llorens et al. 


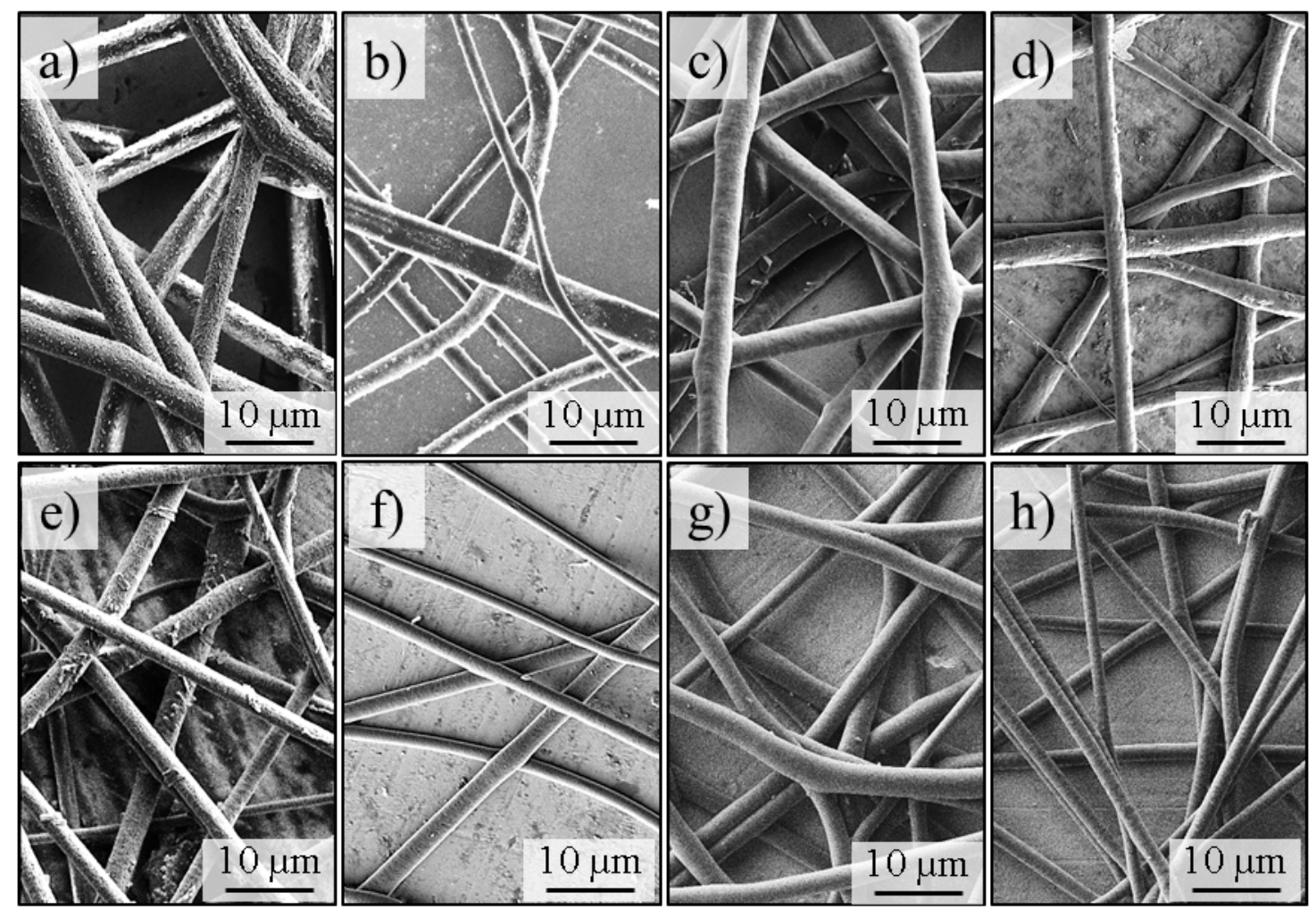

FIGURE 2

Llorens et al. 

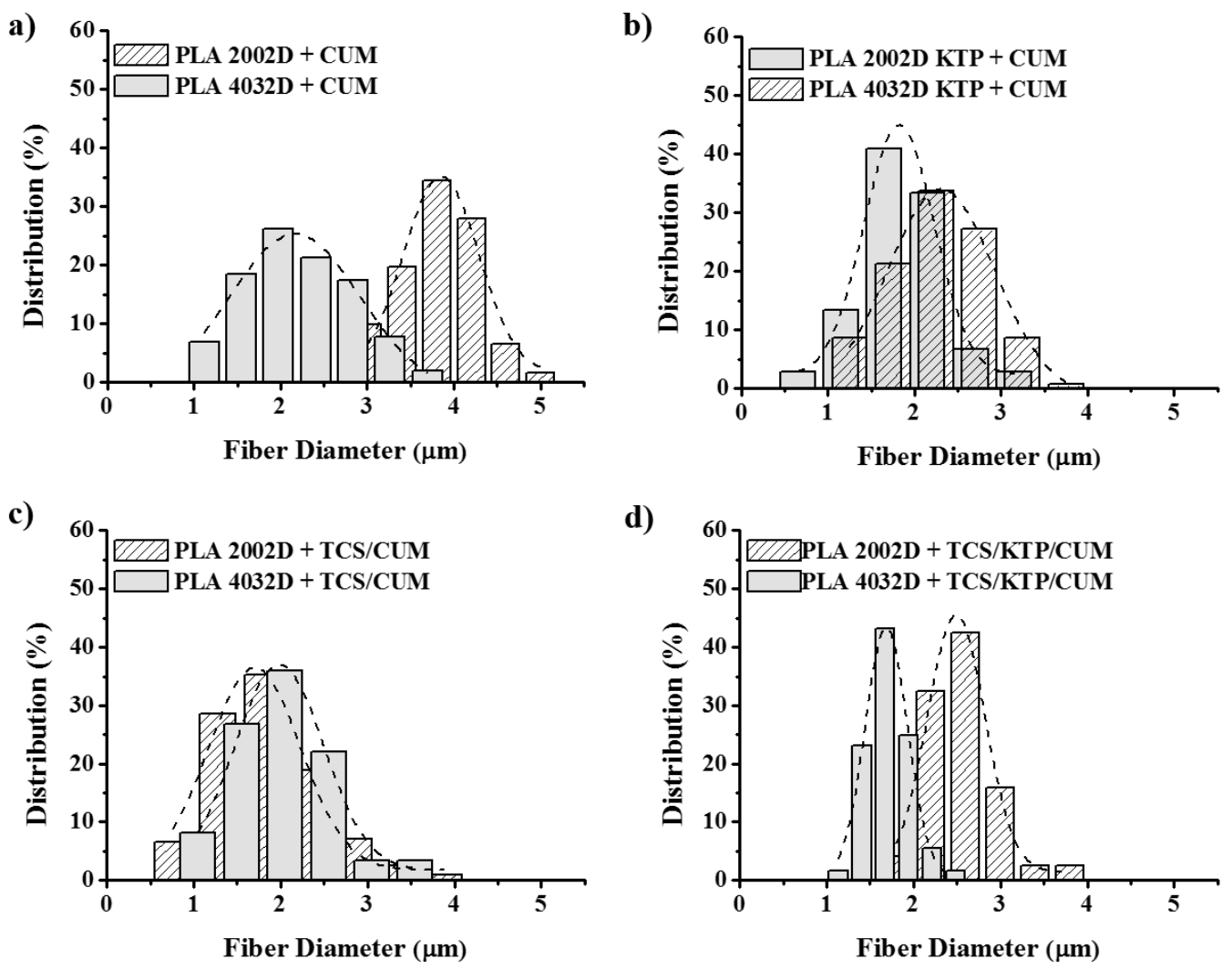

FIGURE 3

Llorens et al. 

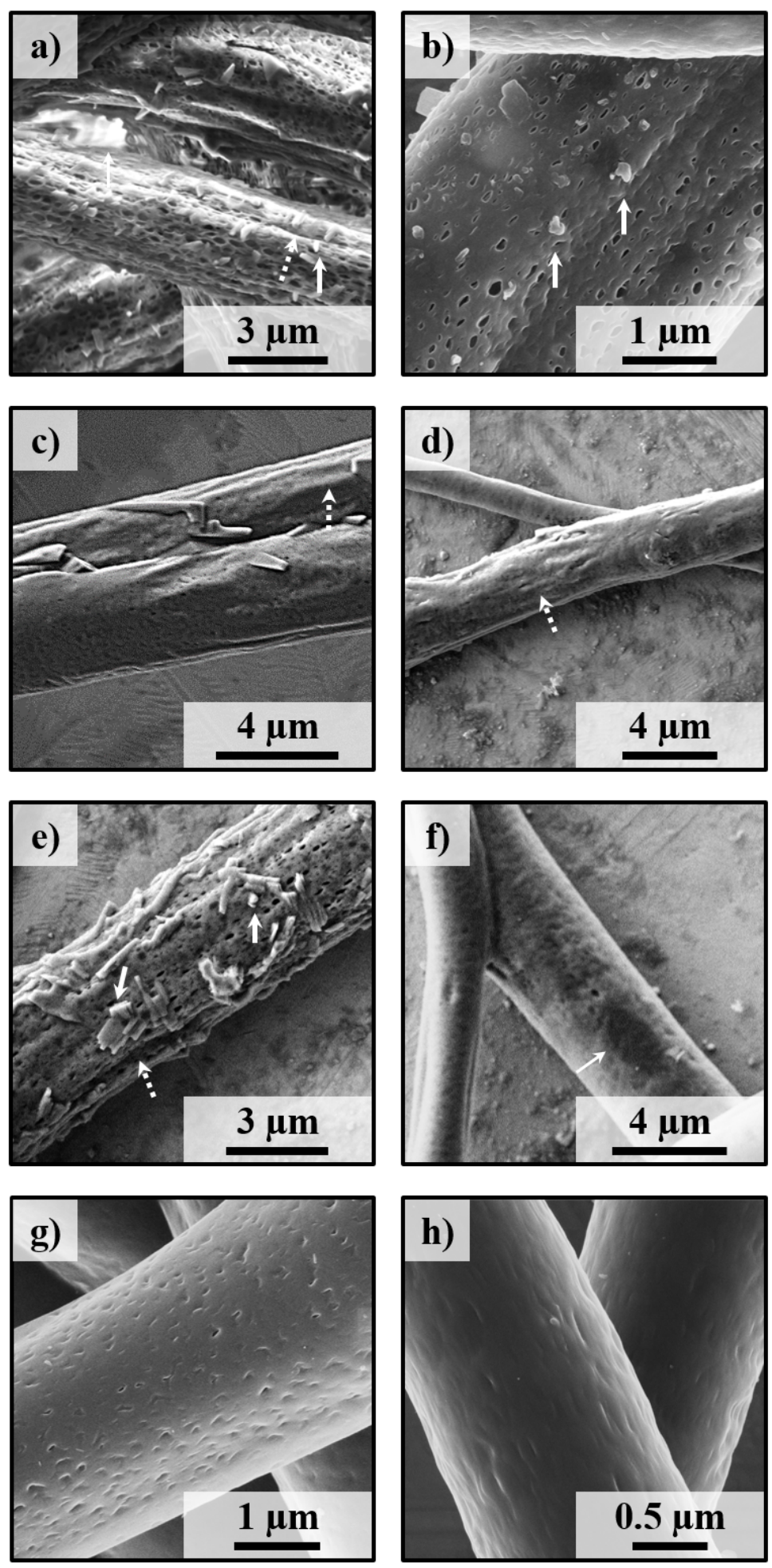

FIGURE 4

Llorens et al. 


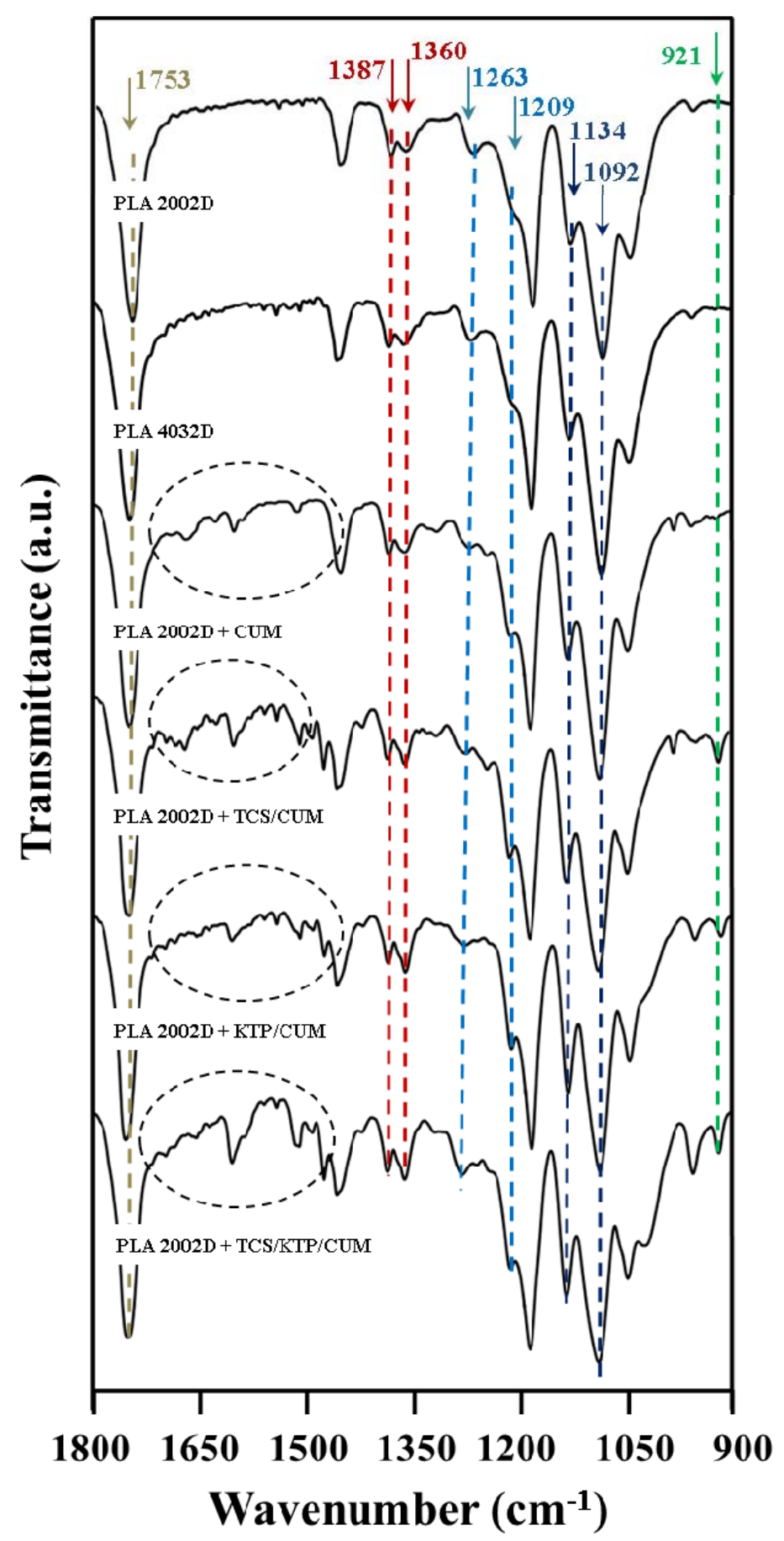

FIGURE 5

Llorens et al. 


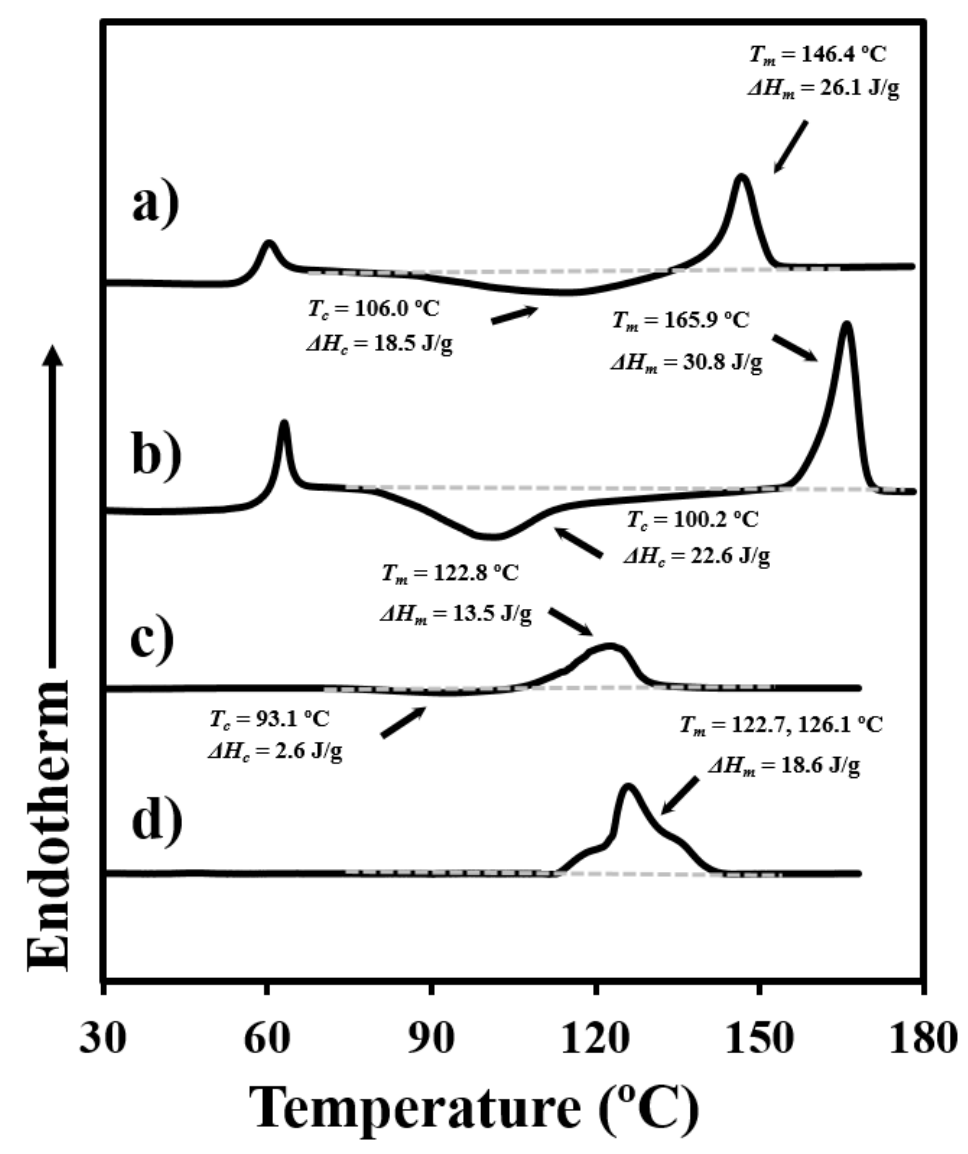

FIGURE 6

Llorens et al. 
a)

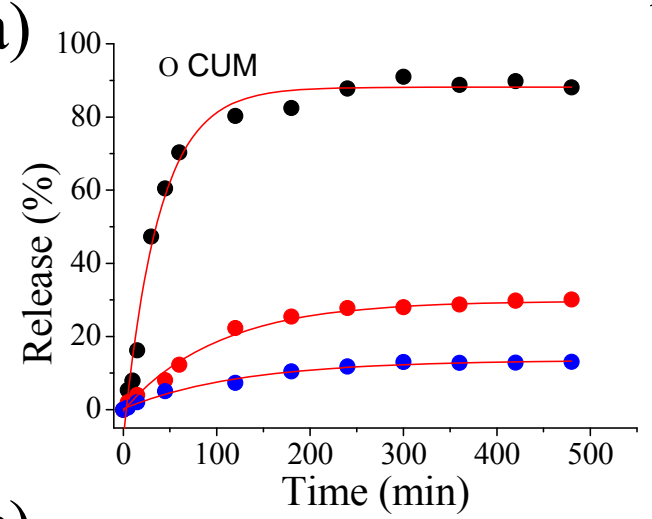

c)

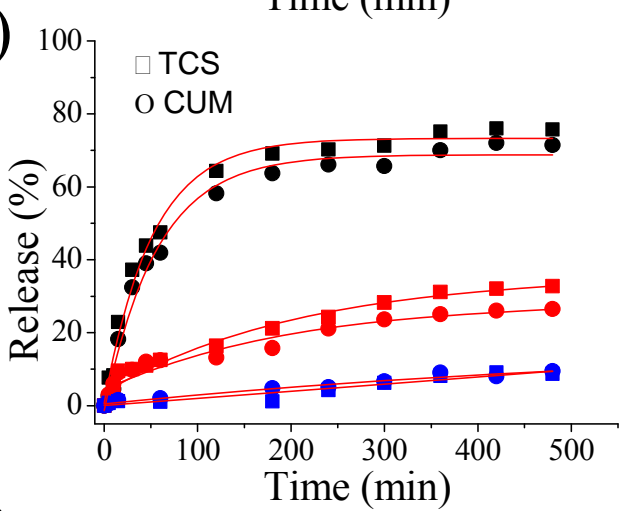

e)

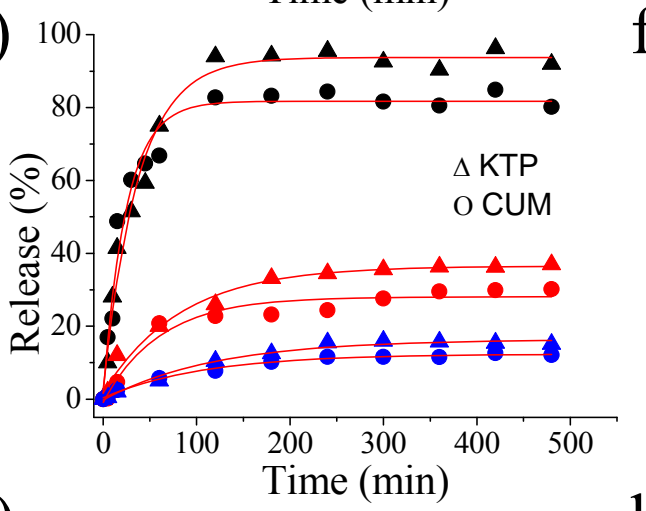

g)

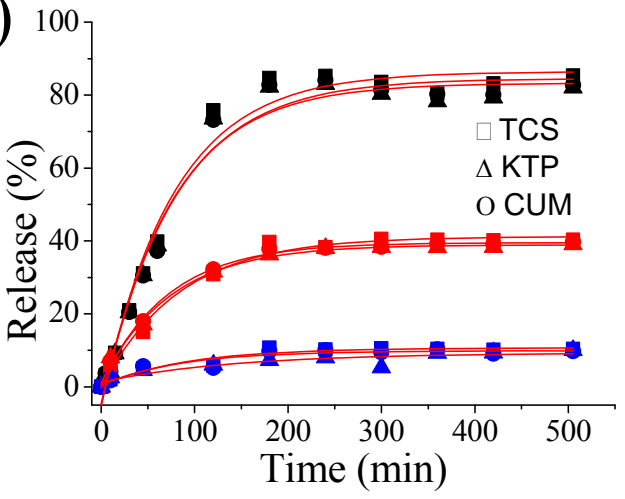

b)

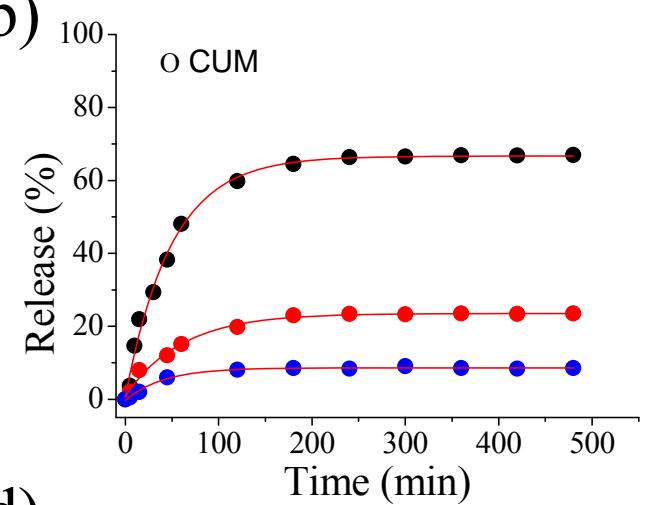

d)

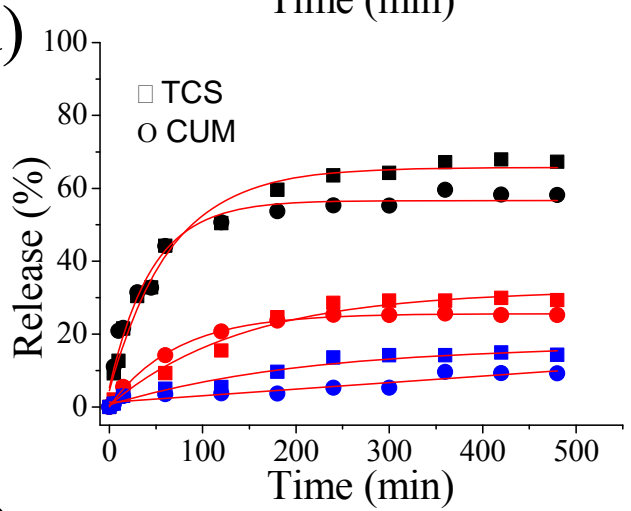

f)

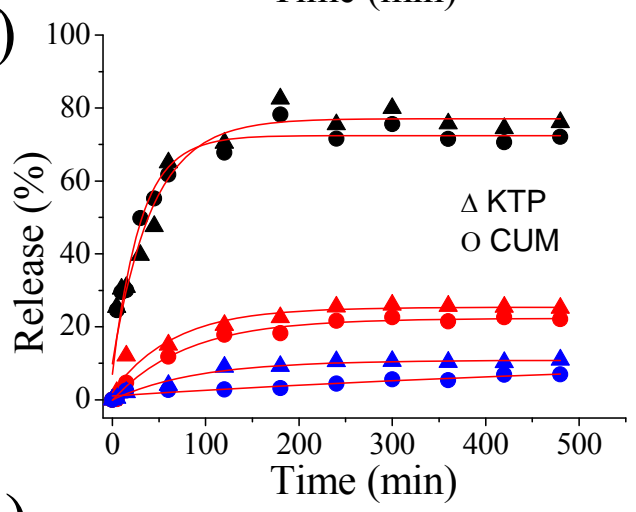

h)

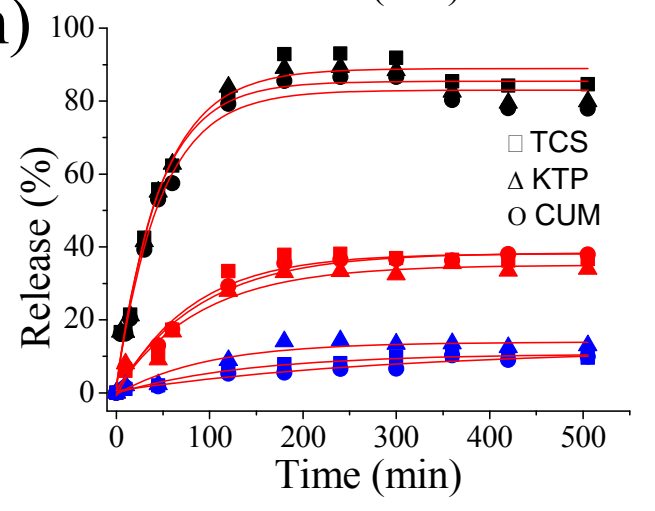

FIGURE 7

Llorens et al. 

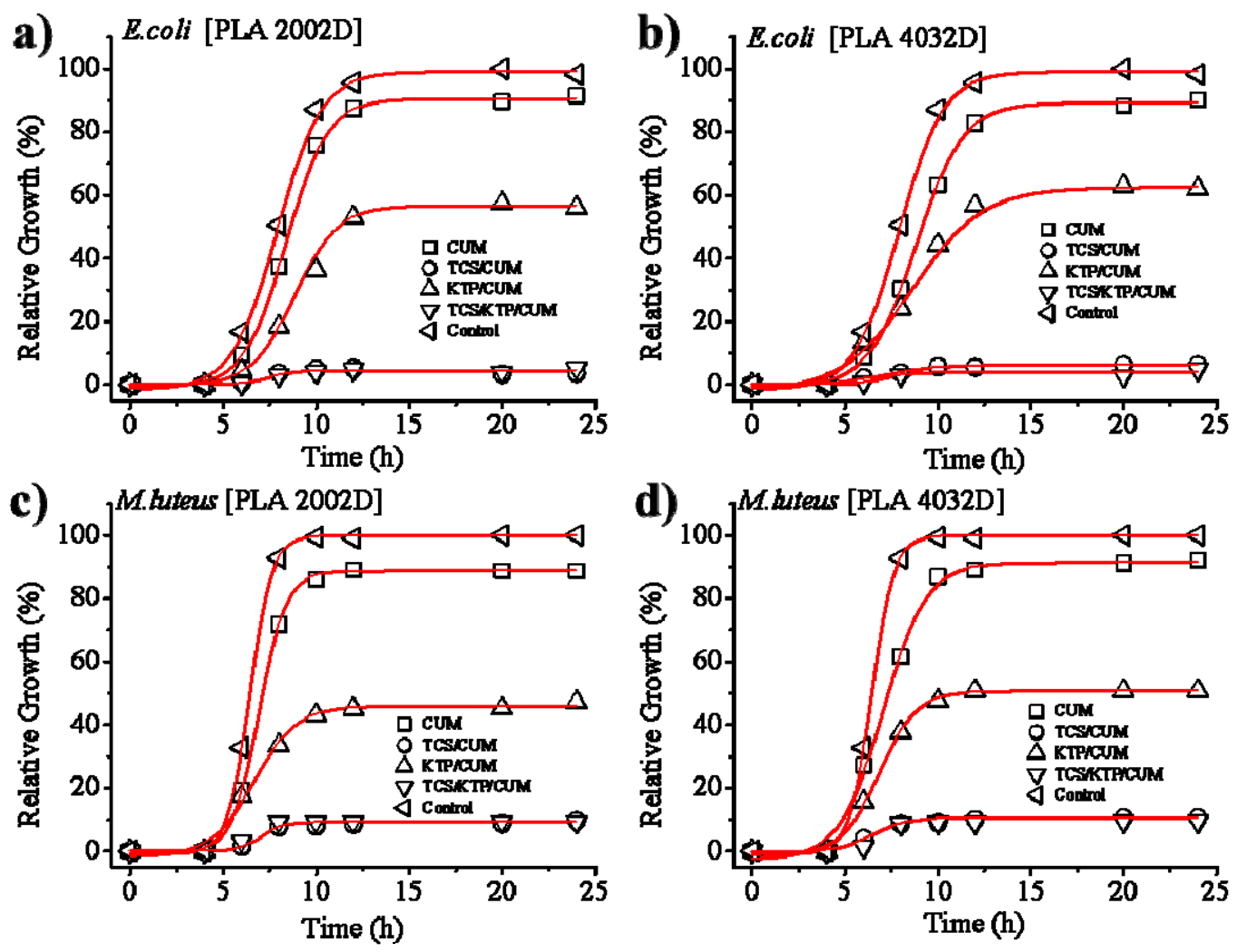

FIGURE 8

Llorens et al. 


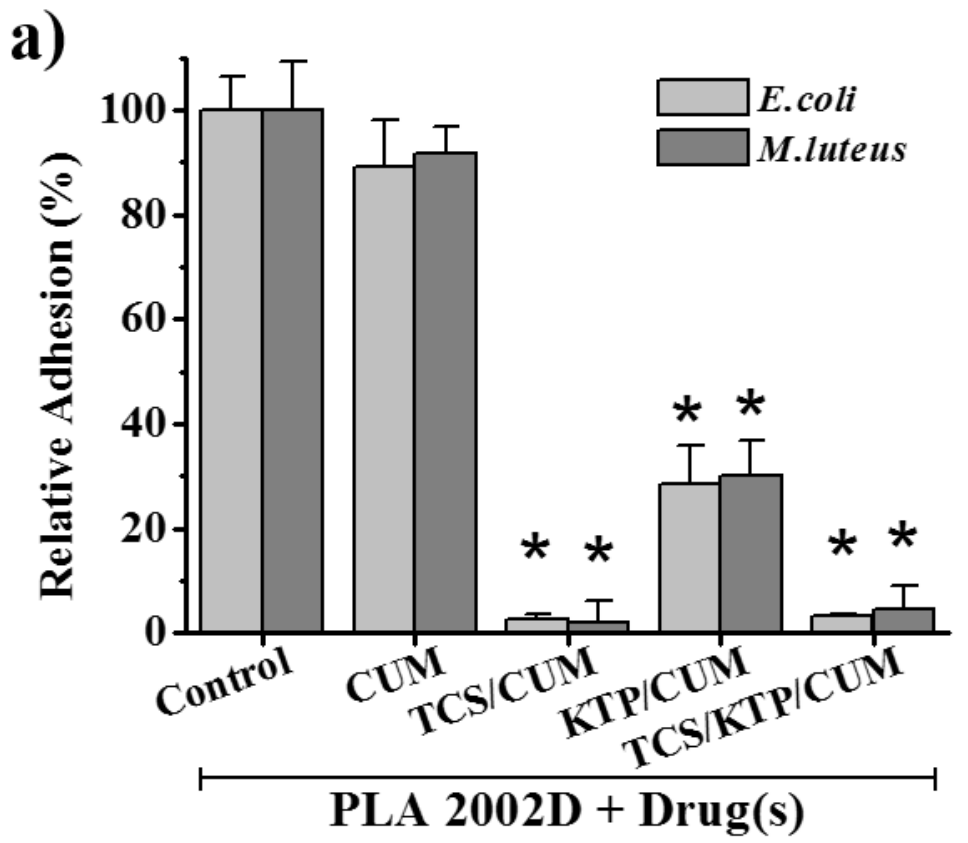

b)

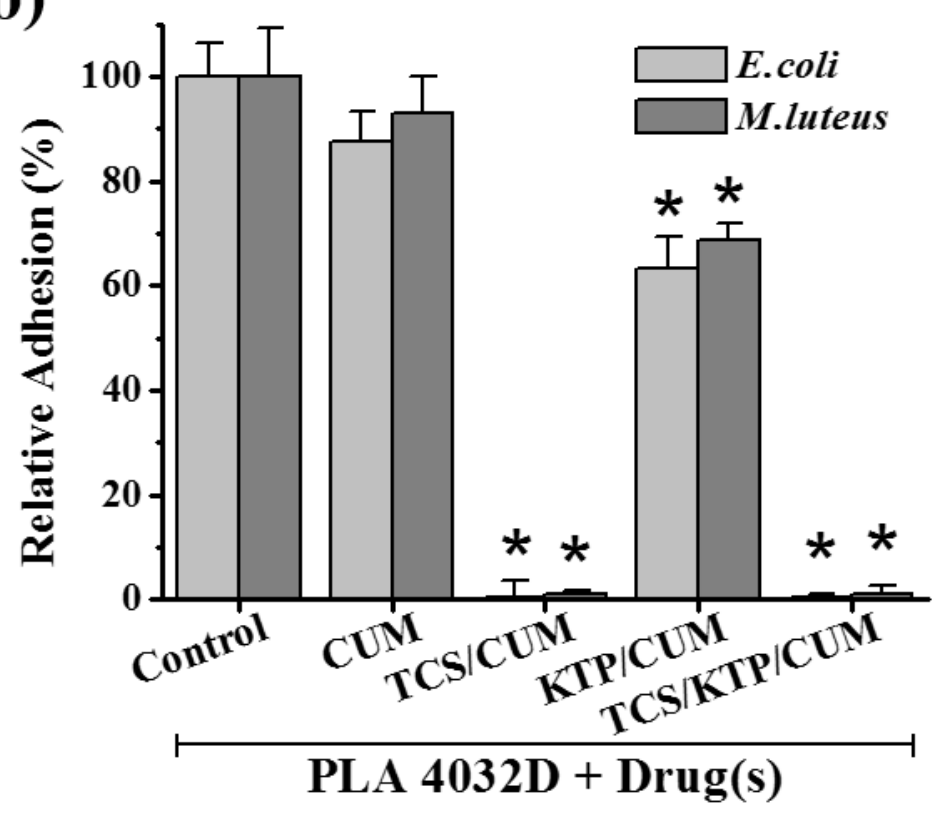

FIGURE 9

Llorens et al. 

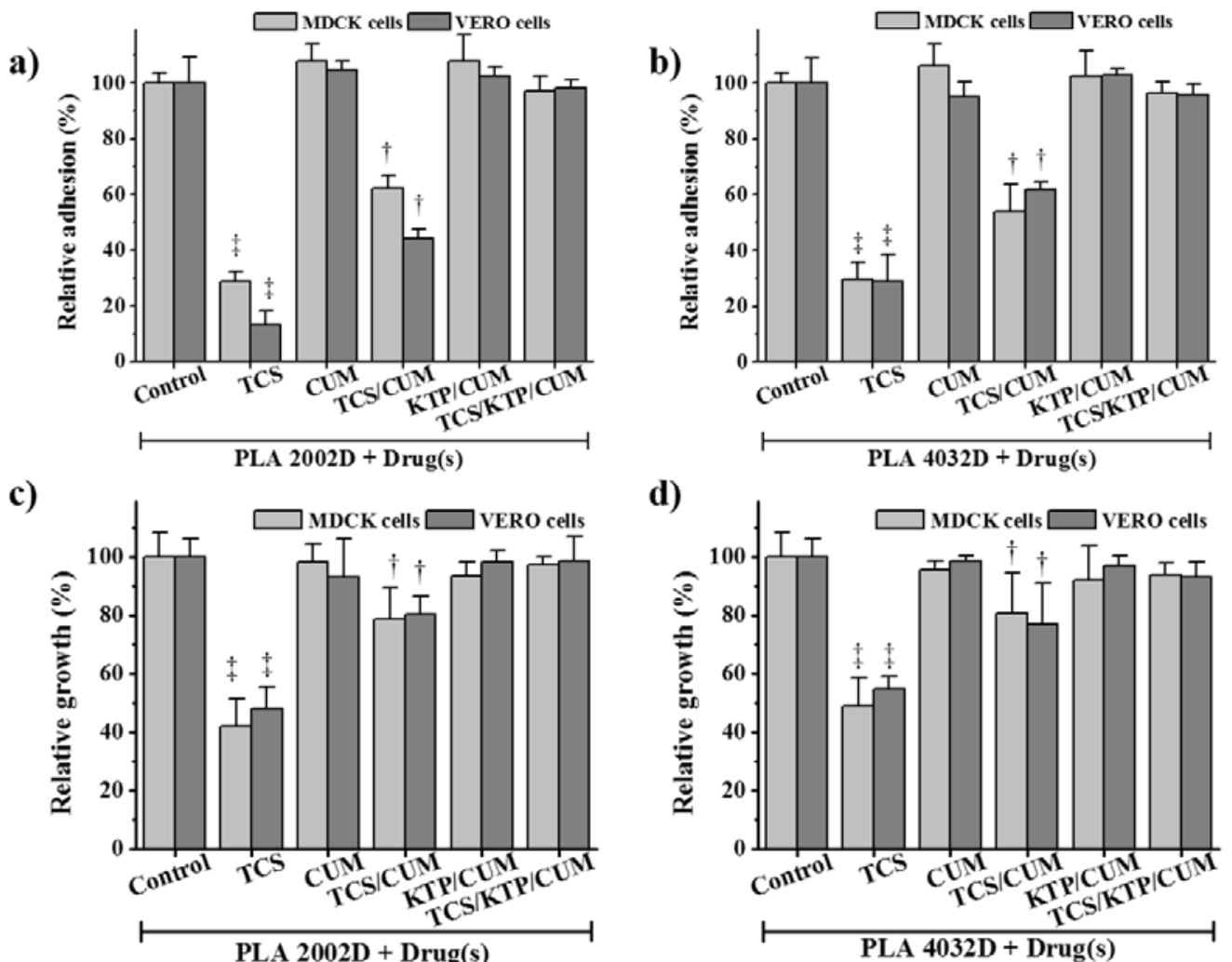

FIGURE 10

Llorens et al. 